\title{
Cis-cis and trans-perp HOONO: Action spectroscopy and isomerization kinetics
}

\author{
Juliane L. Frya) \\ Arthur Amos Noyes Laboratory of Chemical Physics, California Institute of Technology, Pasadena, \\ California 91125 \\ Sergey A. Nizkorodov \\ Department of Chemistry, University of California at Irvine, Irvine, California 92697 \\ Mitchio Okumura ${ }^{\text {b) }}$ \\ Arthur Amos Noyes Laboratory of Chemical Physics, California Institute of Technology, Pasadena, \\ California 91125 \\ Coleen M. Roehl \\ Division of Geological and Planetary Sciences, California Institute of Technology, Pasadena, \\ California 91125 \\ Joseph S. Francisco \\ Department of Chemistry, Purdue University, West Lafayette, Indiana 47907 \\ Paul O. Wennberg ${ }^{\mathrm{c})}$ \\ Division of Geological and Planetary Sciences and Division of Engineering and Applied Science, California \\ Institute of Technology, Pasadena, California 91125
}

(Received 26 January 2004; accepted 21 April 2004)

The weakly bound $\mathrm{HOONO}$ product of the $\mathrm{OH}+\mathrm{NO}_{2}+M$ reaction is studied using the vibrational predissociation that follows excitation of the first $\mathrm{OH}$ overtone $\left(2 \nu_{1}\right)$. We observe formation of both cis-cis and trans-perp conformers of HOONO. The trans-perp HOONO $2 \nu_{1}$ band is observed under thermal $(223-238 \mathrm{~K})$ conditions at $6971 \mathrm{~cm}^{-1}$. We assign the previously published (warmer temperature) HOONO spectrum to the $2 \nu_{1}$ band at $6365 \mathrm{~cm}^{-1}$ and $2 \nu_{1}$-containing combination bands of the cis-cis conformer of HOONO. The band shape of the trans-perp HOONO spectrum is in excellent agreement with the predicted rotational contour based on previous experimental and theoretical results, but the apparent origin of the cis-cis HOONO spectrum at $6365 \mathrm{~cm}^{-1}$ is featureless and significantly broader, suggesting more rapid intramolecular vibrational redistribution or predissociation in the latter isomer. The thermally less stable trans-perp HOONO isomerizes rapidly to cis-cis $\mathrm{HOONO}$ with an experimentally determined lifetime of $39 \mathrm{~ms}$ at $233 \mathrm{~K}$ at $13 \mathrm{hPa}$ (in a buffer gas of predominantly Ar). The temperature dependence of the trans-perp HOONO lifetime in the range $223-238 \mathrm{~K}$ yields an isomerization barrier of $33 \pm 12 \mathrm{~kJ} / \mathrm{mol}$. New ab initio calculations of the structure and vibrational mode frequencies of the transition state perp-perp HOONO are performed using the coupled cluster singles and doubles with perturbative triples $[\mathrm{CCSD}(\mathrm{T})]$ model, using a correlation consistent polarized triple $\zeta$ basis set (cc-pVTZ). The energetics of cis-cis, trans-perp, and perp-perp HOONO are also calculated at this level [CCSD(T)/ cc-pVTZ] and with a quadruple $\zeta$ basis set using the structure determined at the triple $\zeta$ basis set $[\mathrm{CCSD}(\mathrm{T}) / \mathrm{cc}-\mathrm{pVQZ} / / \mathrm{CCSD}(\mathrm{T}) / \mathrm{cc}-\mathrm{pVTZ}]$. These calculations predict that the anti form of perp-perp $\mathrm{HOONO}$ has an energy of $\Delta E_{0}=42.4 \mathrm{~kJ} / \mathrm{mol}$ above trans-perp $\mathrm{HOONO}$, corresponding to an activation enthalpy of $\Delta H_{298}^{\ddagger 0}=41.1 \mathrm{~kJ} / \mathrm{mol}$. These results are in good agreement with statistical simulations based on a model developed by Golden, Barker, and Lohr. The simulated isomerization rates match the observed decay rates when modeled with a trans-perp to cis-cis HOONO isomerization barrier of $40.8 \mathrm{~kJ} / \mathrm{mol}$ and a strong collision model. The quantum yield of cis-cis $\mathrm{HOONO}$ dissociation to $\mathrm{OH}$ and $\mathrm{NO}_{2}$ is also calculated as a function of photon excitation energy in the range $3500-7500 \mathrm{~cm}^{-1}$, assuming $D_{0}=83 \mathrm{~kJ} / \mathrm{mol}$. The quantum yield is predicted to vary from 0.15 to 1 over the observed spectrum at $298 \mathrm{~K}$, leading to band intensities in the action spectrum that are highly temperature dependent; however, the observed relative band strengths in the cis-cis HOONO spectrum do not change substantially with temperature over the range 193-273 K. Semiempirical calculations of the oscillator strengths for $2 \nu_{1}$ (cis-cis HOONO) and $2 \nu_{1}$ (trans-perp HOONO) are performed using (1) a one-dimensional anharmonic model and (2)

\footnotetext{
a) Author to whom correspondence should be addressed; Electronic mail. fry@caltech.edu

b) Author to whom correspondence should be addressed; Electronic mail. mo@caltech.edu

c) Author to whom correspondence should be addressed; Electronic mail. wennberg@gps.caltech.edu
} 
a Morse oscillator model for the $\mathrm{OH}$ stretch, and ab initio dipole moment functions calculated using Becke, Lee, Yang, and Parr density functional theory (B3LYP), Møller-Plesset pertubation theory truncated at the second and third order (MP2 and MP3), and quadratic configuration interaction theory using single and double excitations (QCISD). The QCISD level calculated ratio of $2 \nu_{1}$ oscillator strengths of trans-perp to cis-cis HOONO is 3.7:1. The observed intensities indicate that the concentration of trans-perp $\mathrm{HOONO}$ early in the $\mathrm{OH}+\mathrm{NO}_{2}$ reaction is significantly greater than predicted by a Boltzmann distribution, consistent with statistical predictions of high initial yields of trans-perp $\mathrm{HOONO}$ from the $\mathrm{OH}+\mathrm{NO}_{2}+M$ reaction. In the atmosphere, trans-perp $\mathrm{HOONO}$ will isomerize nearly instantaneously to cis-cis HOONO. Loss of HOONO via photodissociation in the near-IR limits the lifetime of cis-cis HOONO during daylight to less than $45 \mathrm{~h}$, other loss mechanisms will reduce the lifetime further. (C) 2004 American Institute of Physics.

[DOI: $10.1063 / 1.1760714]$

\section{INTRODUCTION}

Knowledge of the concentrations and chemistry of the $\mathrm{HO}_{x}\left(\mathrm{OH}+\mathrm{HO}_{2}\right)$ and $\mathrm{NO}_{x}\left(\mathrm{NO}+\mathrm{NO}_{2}\right)$ families of radicals is central to understanding global atmospheric chemistry. Both families are involved in tropospheric ozone production and stratospheric ozone loss. Hydroxyl radical $(\mathrm{OH})$ has extremely high reactivity with many atmospheric trace gases, and is referred to as an atmospheric detergent because it cleanses the atmosphere of pollutants. $\mathrm{NO}_{x}$ is a major component of photochemical smog.

As the major sink of both $\mathrm{HO}_{x}$ and $\mathrm{NO}_{x}$, the radical termination reaction

$$
\mathrm{OH}+\mathrm{NO}_{2}+M \rightarrow \mathrm{HONO}_{2}+M
$$

is of critical importance in atmospheric chemistry. The rate constant of this reaction has been the topic of some controversy ${ }^{1-7}$ because the high and low pressure rate constants could not be reconciled with a single termolecular rate expression. This discrepancy can be resolved by the inclusion of a second minor channel forming a more weakly bound isomer of nitric acid, peroxynitrous acid, or HOONO, as first predicted by Robertshaw and Smith: ${ }^{8}$

$$
\begin{aligned}
\mathrm{OH}+\mathrm{NO}_{2}+M & \rightarrow \mathrm{HONO}_{2}+M \\
& \rightarrow \mathrm{HOONO}+M .
\end{aligned}
$$

The energetics of $\mathrm{OH}+\mathrm{NO} \rightarrow \mathrm{HOONO}$ and $\mathrm{HONO}_{2}$ are shown in Fig. 1, with relative cis-cis, trans-perp, and perpperp HOONO energies from CCSD(T)/cc-pVQZ/CCSD(T)/ cc-pVTZ [where $\operatorname{CCSD}(\mathrm{T})$ - coupled cluster singles and doubles with perturbative triples, cc-pVTZ - correlation consistent polarized triple $\zeta$ basis set, and cc-pVQZ - correlation consistent quadruple $\zeta$ basis set] level calculations reported in this paper. The energies of $\mathrm{OH}+\mathrm{NO}_{2}$ and $\mathrm{HONO}_{2}$ relative to cis-cis $\mathrm{HOONO}$ are taken from Bean et al. ${ }^{9}$ The formation of $\mathrm{HOONO}$ instead of $\mathrm{HONO}_{2}$ has very different implications for the atmospheric concentrations of $\mathrm{OH}$ and $\mathrm{NO}_{2}$. Since HOONO is more weakly bound than $\mathrm{HONO}_{2}$ (Fig. 1), it will have a short lifetime (on the order of seconds at 300 $\mathrm{K})$ in the lower atmosphere due to efficient thermal dissociation back to $\mathrm{OH}$ and $\mathrm{NO}_{2}$. No evidence has yet been found for direct isomerization of $\mathrm{HOONO}$ into $\mathrm{HONO}_{2},{ }^{7}$ and it is likely to be prevented by a high reaction barrier. ${ }^{10} \mathrm{~A}$ majority of previous kinetics studies of reaction (1) were done via observation of $\mathrm{OH}$ decay in the presence of excess $\mathrm{NO}_{2}$ without taking the HOONO channel into consideration. At some conditions, these experiments measured the total reaction rate coefficient, $k_{1}=k_{1 a}+k_{1 b}$, while assuming the observed decay was due only to $k_{1 a}$. Recent measurements ${ }^{3,9,11}$ have found that HOONO is indeed formed in reaction (1) with a measurable yield of $k_{1 b} /\left(k_{1 a}+k_{1 b}\right) \approx 5-10 \%$ at low pressures $(27 \mathrm{hPa})$ and room temperature. Thus, to the extent that HOONO is formed, the total rate of reaction (1) overestimates the net loss of $\mathrm{HO}_{x}$ and $\mathrm{NO}_{x}$ to $\mathrm{HNO}_{3}$.

The $\mathrm{OH}+\mathrm{NO}_{2}$ system is complicated by the existence of several distinct conformers of HOONO. ${ }^{1,12-14}$ The predicted lowest-energy conformers are cis-cis and trans-perp HOONO (Fig. 1), wherein the first and second prefixes refer to the conformations of the $\mathrm{ONOO}$ and $\mathrm{NOOH}$ dihedral angles, respectively. The planar cis-cis conformer has a weak internal hydrogen bond and is computed to be stabilized relative to the open trans-perp conformer by $15.3 \mathrm{~kJ} / \mathrm{mol}$. A third conformer, cis-perp HOONO, was identified in early ab initio calculations of McGrath and Rowland ${ }^{12}$ and calculated to be $1.7-2.5 \mathrm{~kJ} / \mathrm{mol}$ above cis-cis HOONO. Tsai et al. ${ }^{14}$ and Jin et al. ${ }^{13}$ have calculated cis-perp HOONO energies (relative to cis-cis HOONO) of $3.8-5.4 \mathrm{~kJ} / \mathrm{mol}$ and $-5.1-5.9$ $\mathrm{kJ} / \mathrm{mol}$, respectively. Recent higher-level calculations indicate that the cis-perp conformer may not be a stationary point on the HOONO potential energy surface. ${ }^{2,10}$

Isomerization between the trans-perp and cis-cis conformers of HOONO occurs by rotation about the N-O bond.

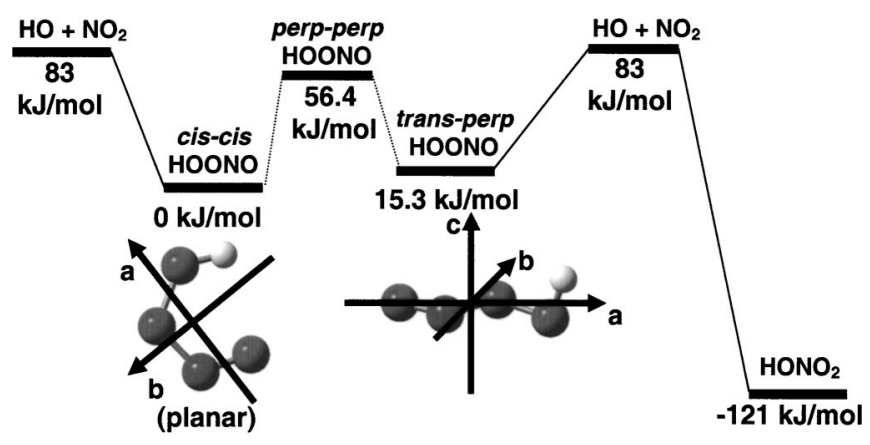

FIG. 1. Energy level diagram for the $\mathrm{OH}+\mathrm{NO}_{2}$ reaction, with structures of trans-perp and cis-cis HOONO shown. HOONO energy levels are from present work; $\mathrm{HONO}_{2}$ energy relative to cis-cis $\mathrm{HOONO}$ are from Bean et al. ${ }^{9}$ and $\mathrm{OH}+\mathrm{NO}_{2}$ energy relative to cis-cis $\mathrm{HOONO}$ is from Hippler, Nasterlack, and Striebel ${ }^{3}$ and Dixon et al. ${ }^{10}$ Pathways for direct isomerization from $\mathrm{HOONO}$ into $\mathrm{HONO}_{2}$ are not shown because they have substantially higher barriers compared to dissociation into $\mathrm{OH}$ and $\mathrm{NO}_{2}$. 
This transition state was first termed perp-perp HOONO by McGrath and Rowland, ${ }^{12}$ because the $\mathrm{OH}$ and $\mathrm{NO}$ bonds are nearly perpendicular to the O-O-N plane. They calculated a transition state energy of $52.3 \mathrm{~kJ} / \mathrm{mol}$ above the cis-cis conformer of HOONO. There are predicted to be two perp-perp conformers, encompassing two transition states of nearly identical energies and similar structures and frequencies. In the anti configuration, the $\mathrm{OH}$ and $\mathrm{NO}$ bonds lie on opposite sides of the NOO plane, in the syn conformation, they are on the same side. Golden, Barker, and Lohr, ${ }^{2}$ Jin et al. ${ }^{13}$ and Tsai et al. ${ }^{14}$ have found that the two perp-perp HOONO conformers have nearly identical energetics. This has led Golden, Barker, and $\mathrm{Lohr}^{2}$ to treat the isomerization from trans-perp to cis-cis HOONO as occurring by a single pathway with a degeneracy of two in statistical calculations.

Vibrational frequencies of various conformers of HOONO have been predicted at several levels of theory. MP2/6-31G $(d)$ calculations (where MP2-Møller-Plesset theory truncated at the second order) of the harmonic vibrational frequencies and infrared intensities of eight conformational structures of HOONO were carried out by McGrath and Rowland. ${ }^{12} \mathrm{Li}$ and Francisco ${ }^{15}$ later calculated vibrational frequencies for cis-cis HOONO at the QCISD(T)/ccpVTZ level (where QCISD—quadratic configuration interaction theory using single and double excitations), and Jin et al. ${ }^{13}$ reported vibrational frequencies for nine structures of HOONO (including the two perp-perp conformers) at the $\mathrm{B} 3 \mathrm{LYP} / 6-311+\mathrm{G}(d, p)$ and MP2/6-311+ $\mathrm{G}(d, p)$ levels (where B3LYP-Becke, Lee, Yang, and Parr density functional theory). Bean et al. ${ }^{9}$ reported vibrational frequencies for both cis-cis and trans-perp HOONO at the CCSD(T)/ccpVTZ level.

Estimates of the dissociation energy of cis-cis HOONO are converging on a value between 76 and $84 \mathrm{~kJ} / \mathrm{mol}$. Among the most recent $a b$ initio calculations of the dissociation energy, $\mathrm{Li}$ and Francisco calculate $D_{0}$ (cis-cis HOONO) $=78.7 \mathrm{~kJ} / \mathrm{mol}$ at the QCISD $(\mathrm{T}) / \mathrm{cc}-\mathrm{pVQZ}$ level, and Dixon et al. calculate two values for $D_{0}$ (cis-cis $\left.\mathrm{HOONO}\right)$ : first, $82.9 \mathrm{~kJ} / \mathrm{mol}$, a strictly $a b$ initio number calculated at the CCSD(T)/CBS (where CBS—complete basis set) level with core/valence corrections to the dissociation energy and molecular scalar relativistic corrections accounting for the change in relativistic contributions to the total energy of the molecular or radical species versus the constituent atoms; second, $76.6 \mathrm{~kJ} / \mathrm{mol}$, using an experimental value for $\Delta H_{f}\left(\mathrm{NO}_{2}\right)$. These calculations give a $6 \mathrm{~kJ} / \mathrm{mol}$ wide bracket for the value of $D_{0}$ (cis-cis HOONO), the width of which demonstrates the uncertainty of the $a b$ initio calculations. Hippler, Nasterlack, and Striebel report the only experimental value, $D_{0}$ (cis-cis $\left.\mathrm{HOONO}\right)=83 \mathrm{~kJ} / \mathrm{mol}$, from a third-law analysis of the equilibrium constants over $430-490 \mathrm{~K}^{3}{ }^{3} \mathrm{~A}$ refinement of the evaluation of this data is underway, and reanalysis of the high temperature data now gives $D_{0}($ cis-cis $\mathrm{HOONO})=80.5 \mathrm{~kJ} / \mathrm{mol}^{16}{ }^{16}$ Pollack et al. ${ }^{17}$ have set an experimental upper limit on the trans-perp HOONO binding energy of $70.3 \mathrm{~kJ} / \mathrm{mol}$ from the product internal energy distribution of the vibrational predissociation of jetcooled trans-perp HOONO. From this limit and the ab initio energy difference between cis-cis and trans-perp HOONO, they find an upper limit for the cis-cis HOONO dissociation energy, $D_{0}($ cis-cis $\mathrm{HOONO}) \leqslant 84.6 \mathrm{~kJ} / \mathrm{mol}$.

There have been several statistical calculations modeling the pressure and temperature dependence and HOONO/ $\mathrm{HONO}_{2}$ branching ratio of this reaction. ${ }^{4,5,18}$ In the most recent study, Golden, Barker, and Lohr ${ }^{2}$ have published a thorough multiwell, multichannel master equation model of the $\mathrm{OH}+\mathrm{NO}_{2}$ system. Their modeling is consistent with previous experimental results, but all such calculations still rely on experimental constraints and cannot predict the behavior of this reaction from first principles.

The first spectroscopic observation of HOONO was a matrix study by Cheng, Lee, and Lee ${ }^{19}$ identifying several fundamental bands $\left(700-3600 \mathrm{~cm}^{-1}\right)$ of both cis-cis and trans-perp $\mathrm{HOONO}$ after photolysis of $\mathrm{HONO}_{2}$ in an $\mathrm{Ar}$ matrix. The first observation of HOONO in the gas phase was the action spectroscopy experiment reported by Nizkorodov and Wennberg ${ }^{11}$ in 2002. In this method, HOONO is excited in the first overtone region by near-IR photons to predissociating states; absorption is monitored by laserinduced fluorescence (LIF) detection of $\mathrm{OH}$ products formed upon dissociation to $\mathrm{OH}$ and $\mathrm{NO}_{2}$. They observed a series of vibrational bands in the first $\mathrm{OH}$ overtone spectral range from products of reaction (1) occurring in a flowing discharge cell, and provided tentative assignments of the bands in terms of the three conformers of HOONO.

The work of Nizkorodov and Wennberg was followed by observation of the $\mathrm{OH}$ stretching fundamental of cis-cis HOONO at $3306 \mathrm{~cm}^{-1}$ in direct absorption by cavity ring down spectroscopy. ${ }^{9}$ Bean et al. determined the yield of HOONO in reaction (1) by directly measuring the integrated vibrational bands of cis-cis $\mathrm{HOONO}$ and $\mathrm{HONO}_{2}$; however, they were unable to detect trans-perp isomer because its spectrum is obscured by the strong nitric acid band. They assumed, with support from statistical calculations, that any trans-perp HOONO formed in reaction (1) had isomerized to cis-cis HOONO in their experiment. Subsequently, Pollack et al. definitively identified the first $\mathrm{OH}$ stretching overtone of supersonically cooled trans-perp HOONO from the rotational band contours detected with photodissociation action spectroscopy. ${ }^{17}$ Though the band origin at $6971.4 \mathrm{~cm}^{-1}$ lies close to the strongest band seen by Nizkorodov and Wennberg, the band is expected to be substantially narrower even at room temperature.

Several key issues remain unresolved, chief among them the question of whether trans-perp HOONO is produced in reaction (1) under thermal conditions. Statistical calculations indicate that this isomer will be formed in a high, nonthermal yield from this reaction; if so, then what is its spectroscopic signature, and how rapidly does it isomerize to cis-cis HOONO? The assignment of the bands seen in the HOONO overtone action spectrum reported by Nizkorodov and Wennberg remains unclear, especially given the new spectroscopic studies and recent $a b$ initio studies suggesting that cis-perp HOONO structure is not stable., ${ }^{2,10}$ If the spectrum is assigned to the cis-cis HOONO conformer, then the dissociation energy $D_{0}$ of this conformer is critical for interpreting the action spectrum, since the action spectrum requires that 
the molecule undergo vibrational predissociation to $\mathrm{OH}$ $+\mathrm{NO}_{2}$ after absorption of a near-IR photon. Current estimates of the dissociation energy are greater than the photon energy for most of the observed bands, implying that the quantum yield is less than unity for much of the spectrum.

In this paper, we reexamine the spectroscopy and isomerization kinetics of HOONO conformers in a discharge flow cell using the predissociation action spectroscopy approach of Nizkorodov and Wennberg. The goal of this study is to reconcile all of the spectroscopic measurements and to provide experimental and theoretical results on the relative energies and reaction barriers on the HOONO potential energy surface. Specifically, we seek to detect the conformers of HOONO by action spectroscopy, and to measure directly the rate and activation energy for isomerization of trans-perp HOONO to cis-cis HOONO. We apply statistical RRKM (Rice-Ramsperger-Kassel-Marcus) theory to calculate the isomerization rates, for comparison to the experimental data, and to predict photodissociation quantum yield of cis-cis $\mathrm{HOONO}$ to $\mathrm{OH}+\mathrm{NO}_{2}$. We perform $\mathrm{CCSD}(\mathrm{T})$ calculations to improve on predictions of the structure, energy, and frequencies of the isomerization transition state (anti configuration of the perp-perp HOONO structure), and refine the relative energetics of the cis-cis, trans-perp, and (anti-)perpperp HOONO conformers. Finally, we calculate the oscillator strengths of both stable conformers, cis-cis and transperp HOONO. The calculated intensities allow us to estimate the cis-cis and trans-perp HOONO yields in our experiment, and to predict the lifetime of HOONO in the atmosphere due to predissociation by near-IR radiation.

\section{EXPERIMENTAL DETAILS}

\section{A. Action spectroscopy}

We investigate the spectroscopy and isomerization kinetics of HOONO conformers using photodissociation action spectroscopy. In this method, HOONO undergoes vibrational predissociation upon absorption of a near-IR photon. The excitation is to the first overtone of the $\mathrm{OH}$ stretch vibration $\left(2 \nu_{1}\right)$, and the resulting $\mathrm{OH}$ fragment is detected via LIF. This technique combines molecular selectivity with very high sensitivity: The more stable isomer of nitric acid, $\mathrm{HONO}_{2}$, will not dissociate at this energy, and the LIF method is sensitive to as few as $10^{4} \mathrm{OH}$ molecules $/ \mathrm{cm}^{3}{ }^{20}$ The experimental apparatus consists of two synchronized lasers to produce the pump (IR) and probe (UV) pulses, a flow cell and reaction chamber, and a photon-counting photomultiplier tube (PMT) detector mounted above the gas flow and lasers. A schematic overview is shown in Fig. 2.

\section{B. Flow cell and generation of $\mathrm{OH}$ radicals and HOONO}

Gases are mixed in a $50 \mathrm{~cm}$ temperature controlled jacketed glass flow cell of $25 \mathrm{~mm}$ internal diameter. The flow cell has a movable injector, and the interior is coated with Teflon to minimize the occurrence of heterogeneous chemistry on the walls.

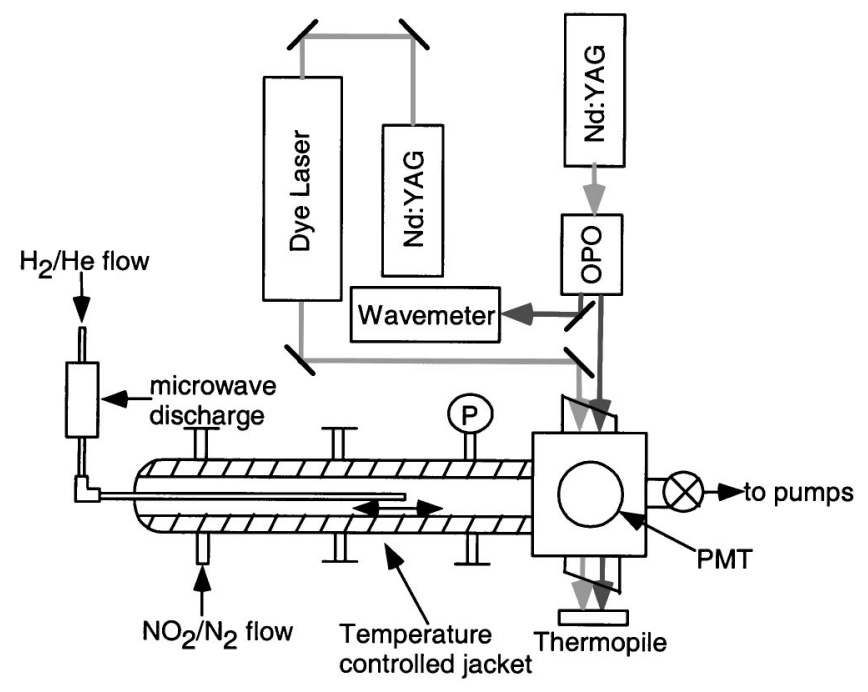

FIG. 2. Schematic of the experimental apparatus. The pulsed $(100 \mathrm{~Hz})$ tunable infrared $(1.3-1.6 \mu \mathrm{m})$ for photolysis of HOONO and pulsed tunable ultraviolet (280-285 nm) for OH LIF enter the detection chamber perpendicular to the gas flow. A PMT detector, behind a $311 \mathrm{~nm}$ bandpass filter, at $90^{\circ}$ to the flows and the lasers, detects the OH LIF. HOONO is produced in a temperature controlled (200-280 K) flow cell via gas-phase chemistry. The time delay between the formation of HOONO and its detection can be varied by adjusting the flow rate and position of the $\mathrm{H}$-atom injector.

In a $2450 \mathrm{MHz}$ McCarroll cavity microwave discharge, $\mathrm{H}_{2}$ gas is converted to $\mathrm{H}$ atoms in the presence of buffer Ar. The $\mathrm{H}$ atoms react to form $\mathrm{OH}$ radicals rapidly upon mixing with flow containing $\mathrm{NO}_{2}$ :

$$
\mathrm{H}+\mathrm{NO}_{2} \rightarrow \mathrm{OH}+\mathrm{NO}
$$

The $\mathrm{OH}$ quickly reacts with another $\mathrm{NO}_{2}$ molecule, forming nitric acid and HOONO conformers [reactions (1a) and (1b)]. Under optimized conditions, the flow cell pressure is $13 \mathrm{hPa}$ and the flow consists of 300 SCCM (SCCM denotes cubic centimeter per minute at STP) Ar and 60 SCCM $1 \% \mathrm{H}_{2}$ in $\mathrm{He}$ through the discharge mixed with 50 SCCM $4 \% \mathrm{NO}_{2}$ in $\mathrm{N}_{2}$. This corresponds to $1.5 \% \mathrm{H}_{2}, 0.5 \% \mathrm{NO}_{2}$, $72 \% \mathrm{Ar}, 14 \% \mathrm{He}$, and $12 \% \mathrm{~N}_{2}$.

The reaction $\mathrm{OH}+\mathrm{NO}_{2}+M \rightarrow \mathrm{HNO}_{3}+M$ occurs on a microsecond time scale in the temperature range $200-280 \mathrm{~K}$ of the flow cell. At the injector port, however, the local temperature of the mixing gases is higher than the controlled flow cell wall temperature due to the highly exothermic reactions (2) and (1). We cannot, therefore, quantitatively treat the formation kinetics of HOONO. This is not a concern in the experiments reported here, since the isomerization kinetics take place on a longer time scale $(60-90 \mathrm{~ms})$.

\section{Lasers and detection}

Reaction products are probed in a laser interaction region downstream from the injector at a distance which varies from 20 to $40 \mathrm{~cm}$. The flowing gas is crossed by two lasers, an infrared laser for vibrational overtone excitation followed by a UV laser to probe $\mathrm{OH}$ products by laser induced fluorescence.

The tunable near IR is generated in a type-II beta- $\mathrm{BaB}_{2} \mathrm{O}_{4}$ (BBO) optical parametric oscillator (OPO) pumped by the $355 \mathrm{~nm}$ third harmonic of a pulsed Nd:YAG (yttrium aluminum garnet) laser $\left(3 \mathrm{~cm}^{-1}\right.$ bandwidth). This 


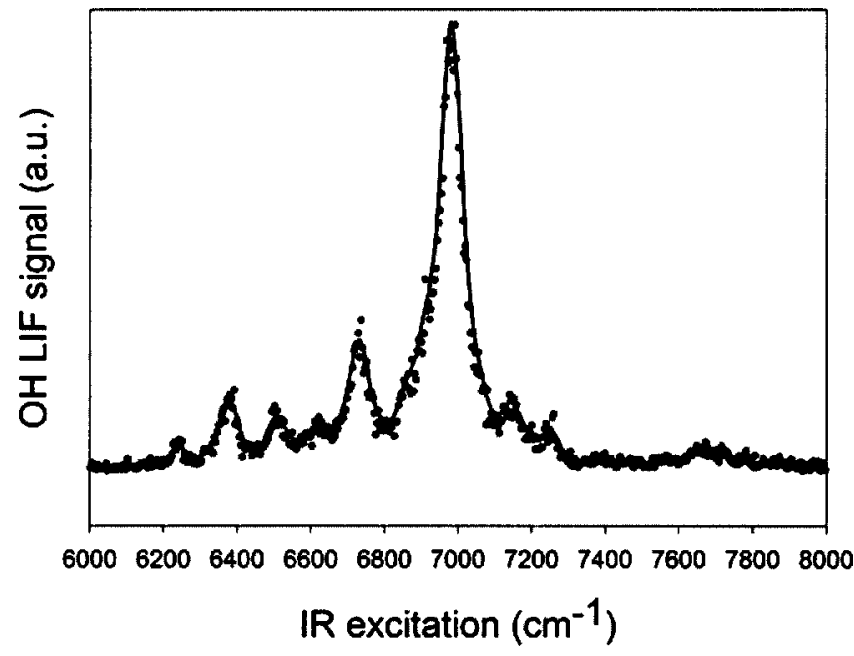

FIG. 3. Averaged HOONO action spectrum obtained at $T=213 \mathrm{~K}, P$ $=13 \mathrm{hPa}$. Previously unobserved features at 6250,6971 , and $7700 \mathrm{~cm}^{-1}$ are seen in the spectrum.

OPO (Ref. 21) outputs $2-3 \mathrm{~mJ} /$ pulse in the idler beam, tunable in the range $800-2500 \mathrm{~nm}\left(4000-12500 \mathrm{~cm}^{-1}\right)$ by rotation of the BBO crystals. The frequency of the signal beam is continuously monitored by a pulsed wavemeter. The wavemeter calibration is verified using photoacoustic spectroscopy of the well-known water transitions in the 7000$7200 \mathrm{~cm}^{-1}$ region. ${ }^{22}$

The IR pump beam passes through the detection chamber via Brewster-angle $\mathrm{CaF}_{2}$ windows, perpendicular to the gas flow, and is measured by a thermal power meter after exiting the chamber for calibration of laser power fluctuations. It is overlapped spatially with the UV output of a second laser system, the second harmonic of a Rhodamine $6 \mathrm{G}$ dye laser pumped by a frequency doubled Nd:YAG laser $\left(\sim 0.2 \mathrm{~cm}^{-1}\right.$ bandwidth).

The UV beam $(<1 \mu \mathrm{J}$, tunable $280-282 \mathrm{~nm})$ excites $\mathrm{OH}$ in the $A^{2} \Sigma(v=1) \leftarrow X^{2} \Pi(v=0)$ band. The $A^{2} \Sigma(v=1)$ $\mathrm{OH}$ relaxes via collisions to the $v=0$ state and fluorescence is observed at $309 \mathrm{~nm}\left[A^{2} \Sigma(v=0) \rightarrow X^{2} \Pi(v=0)\right]$. The LIF signal is focused onto a bialkali photomultiplier tube mounted above the detection region, at right angles to both the laser beams and the gas flow. A narrow band filter with 6 $\mathrm{nm}$ transmission bandwidth centered at $310 \mathrm{~nm}$ is employed to reject scattered UV and visible laser light.

For the data reported here, several modes of data acquisition are used. In the pump scanning mode, the IR pump beam is scanned over the $2 \nu_{1}$ region of the HOONO spectrum, while the UV probe beam is maintained tuned on the strongest OH LIF feature $\left[Q_{21}(1)+Q_{11}(1)+R_{22}(3)\right.$ unresolved triplet of lines]. This yields action spectra, such as Figs. $3-5$, in which the signal at each wavelength is proportional to the product of the absorption cross section and the quantum yield for photodissociation. In this mode, the pumpprobe delay is set to $1 \mu \mathrm{s}$. This ensures a thermalized $\mathrm{OH}$ distribution, so that relative quantum yields from different bands are unaffected by differences in initially formed $\mathrm{OH}$ rotational state distribution. In the probe scanning mode, used to measure $\mathrm{OH}$ product state distribution shown in Fig. 6 , the IR pump beam is tuned to a wavelength corresponding

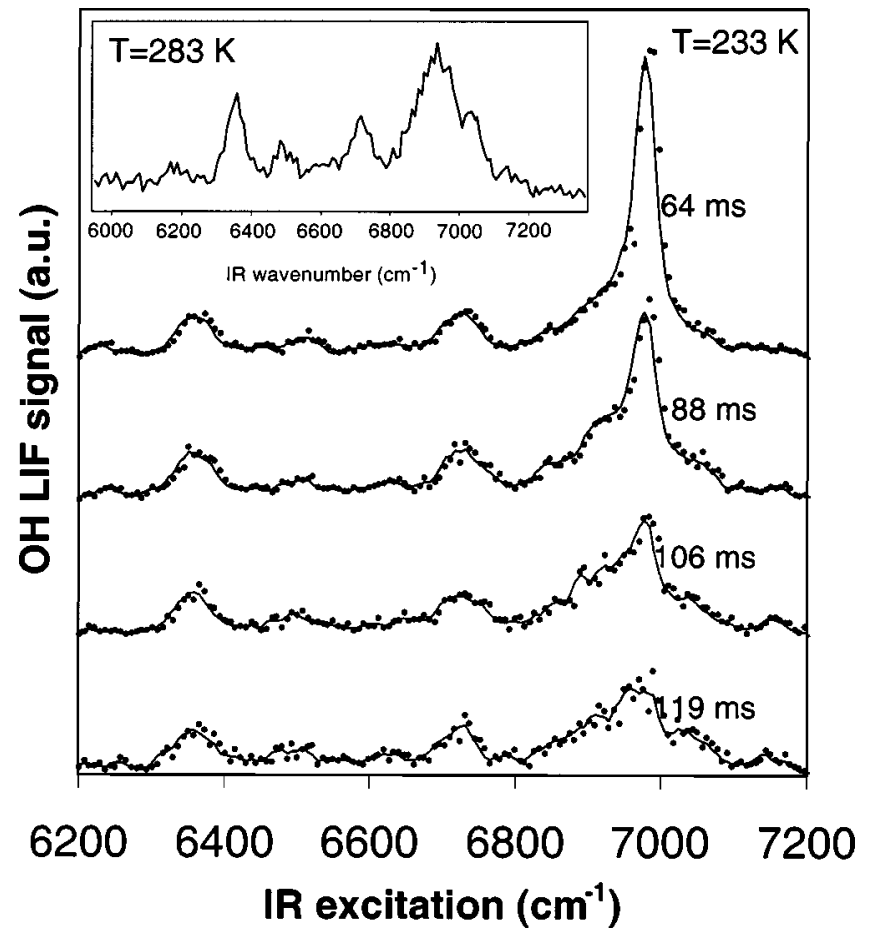

FIG. 4. HOONO action spectra at various flow cell residence times obtained at $T=233 \mathrm{~K}, P=13 \mathrm{hPa}$. Three spectra have been averaged at each residence time, and all spectra are scaled to the same $6365 \mathrm{~cm}^{-1}$ peak intensity. The prominent band at $6971 \mathrm{~cm}^{-1}$ is assigned to trans-perp HOONO. The trans-perp HOONO band decays relative to the cis-cis HOONO band on the $\sim 100 \mathrm{~ms}$ time scale. Inset: $283 \mathrm{~K}$ spectrum of the same region contains cis-cis HOONO bands only. This spectrum was obtained with flow conditions and averaging identical to the $T=233 \mathrm{~K}$ spectra.

to a particular overtone band of the molecule of interest, and the UV LIF probe beam is scanned over several $\mathrm{OH}$ features corresponding to different $N$ states of the photolysis product $\mathrm{OH}$. In this mode, the pump-probe timing is set to the minimum possible delay, $50 \mathrm{~ns}$, to capture the nascent $\mathrm{OH}$ rotational state distribution. Because of the 50 ns delay between pump and probe beams and the relatively high flow cell pressure, $13 \mathrm{hPa}$, the measured $\mathrm{OH}$ product state distribution is some what relaxed by rotational energy transfer from the nascent $\mathrm{OH}$ distribution produced in photodissociation. However, qualitative differentiation between chemical species is still possible. In the flow kinetics mode, used to generate Fig. 7, the IR pump beam is toggled between three wavelengths of interest corresponding to various combinations of the two conformers. The subsequent data analysis to obtain isomerization lifetimes is described below in Sec. IIIC. Again, the UV probe beam is tuned on the strongest $\mathrm{OH}$ LIF feature. Results of all three modes of operation described above will be reported below.

\section{EXPERIMENTAL RESULTS}

\section{A. New transient trans-perp HOONO spectrum}

At room temperature, we observe the same spectrum previously reported by Nizkorodov and Wennberg. ${ }^{11}$ However, upon cooling the flow cell to below $243 \mathrm{~K}$, a new spectral feature emerges on top of the earlier spectrum (Fig. $3)$. The feature is centered at $6971 \mathrm{~cm}^{-1}$ with a width of $\sim 30$ $\mathrm{cm}^{-1}$, substantially narrower than the bands seen in the room 

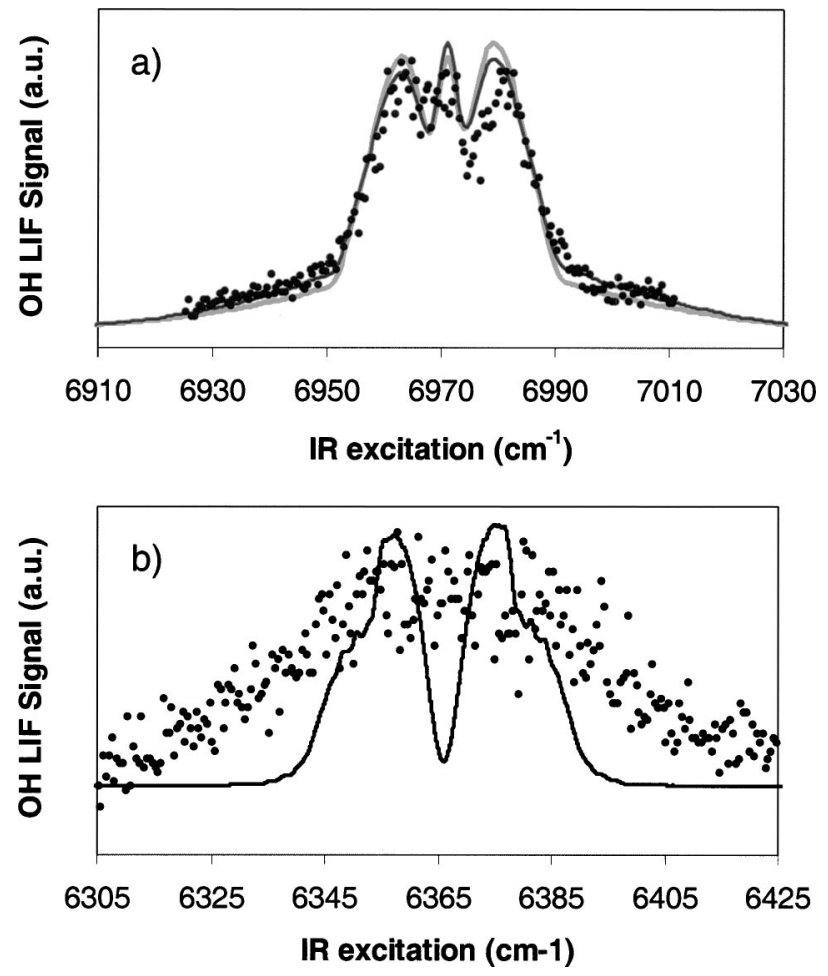

FIG. 5. (a) Action spectrum of trans-perp HOONO at $213 \mathrm{~K}$. A slow scan $\left(0.05 \mathrm{~cm}^{-1}\right.$ step size; $3 \mathrm{~cm}^{-1}$ resolution) over the narrow peak in Fig. 3 reveals band structure. Smooth lines are simulations from the program ASYROTWIN (Ref. 23) using molecular parameters from Table I. Black and gray solid lines are band simulations for an $a$-type to $c$-type ratio of 1.8 and 1 , respectively. The $a$-type/c-type ratio of 1.8 is the hybrid band type calculated in this paper; while the $a$-type/c-type ratio of 1 is the approximate band type for trans-perp HOONO found by Pollack et al. to best represent their experimental spectrum in a supersonic expansion. (b) Action spectrum of $2 \nu_{1}$ band of cis-cis HOONO at $273 \mathrm{~K}$. A slow scan (points) reveals no resolvable structure. Line is a simulation of a pure $b$-type transition, using the program ASYROTWIN (Ref. 23) with cis-cis HOONO molecular parameters from Table I.

temperature spectrum. Figure 3 shows an averaged spectrum of $\mathrm{HOONO}$ at $213 \mathrm{~K}$. With decreasing temperature, this band rapidly grows in intensity relative to the other observed bands. The relative intensity of this feature also depends on the time delay between mixing $\mathrm{H}$ and $\mathrm{NO}_{2}$ inside the flow cell and detection of HOONO in the main chamber. The apparent lifetime of the narrow band at this temperature is in the 100 ms range (Fig. 4). The transient nature of this feature is consistent with a less stable conformer of HOONO, which isomerizes to a more stable conformer or undergoes some other reaction on a millisecond time scale. The peak position is consistent with the overtone frequency predicted for the free $\mathrm{OH}$ bond in trans-perp conformer of HOONO and the overtone band recently fit as trans-perp HOONO in a pulsed supersonic expansion $(5 \mathrm{~K})$ by Pollack et al. ${ }^{17}$ We therefore assign this new spectrum to the trans-perp conformer of HOONO.

This assignment can be confirmed by examination of the observed band shape. Figure 5(a) shows a $3 \mathrm{~cm}^{-1}$ resolution action spectrum of the $6971 \mathrm{~cm}^{-1}$ peak at $213 \mathrm{~K}$ along with rotational band contour simulations performed with the ASYROTWIN program. ${ }^{23}$ We used the calculated rotational constants shown in Table I and assumed the same constants for

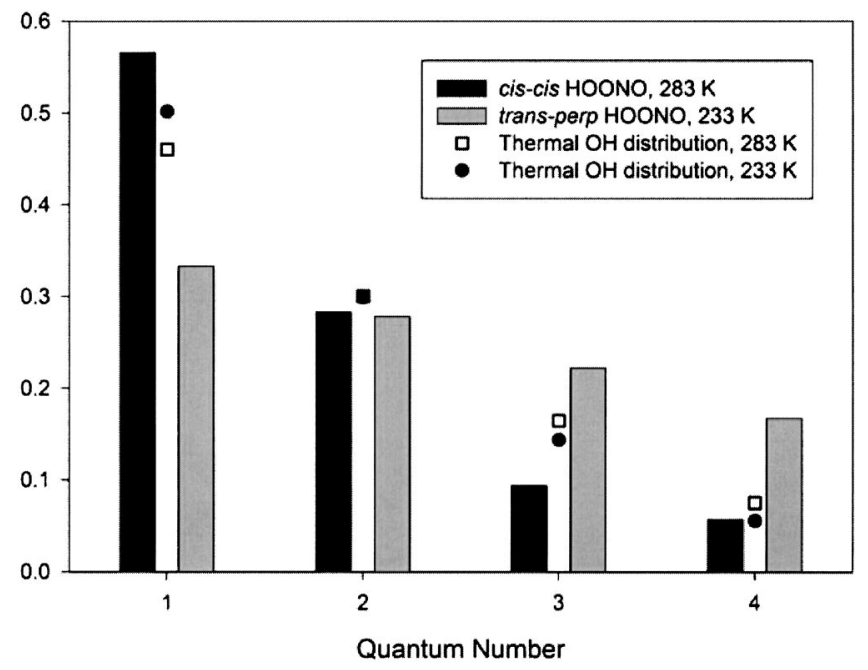

FIG. 6. Relative populations of the first few $\mathrm{OH}^{2} \Pi_{3 / 2}^{-}(N)$ rotational states, $N=1-4$. Black bars represent normalized population of the lowest quantum states after IR photodissociation on a cis-cis HOONO band at $6365 \mathrm{~cm}^{-1}$ at $283 \mathrm{~K}$; gray bars, after photodissociation on a trans-perp HOONO band at $6970 \mathrm{~cm}^{-1}$ at $233 \mathrm{~K}$. Both cis-cis and trans-perp HOONO measurements were conducted at $13 \mathrm{hPa}, 50 \mathrm{~ns}$ pump-probe delay. Symbols indicate thermal $\mathrm{OH}$ distribution at the two temperatures. Large difference in the $\mathrm{OH}$ fragment internal energy reflects the difference in the photon energy available for dissociation.

upper and lower states, in a mixed $a$-type and $c$-type hybrid band. The first simulation [dark line, Fig. 5(a)], which used the $a$-type to $c$-type ratio of 1.8 derived from $a b$ initio calculations of the trans-perp HOONO overtone transition moments discussed in Sec. IV D, matches our $213 \mathrm{~K}$ flow cell spectrum very well. Also shown for comparison is a simulation with an $a$-type to $c$-type band ratio of 1 , a ratio which Pollack et al. ${ }^{17}$ found to give the best representation of their $5 \mathrm{~K}$ spectrum of trans-perp HOONO [gray line, Fig. 5(a)].

In the room temperature spectrum, all of the subbands behave similarly with respect to changes in chemistry and temperature. This multiple-band spectrum is present without

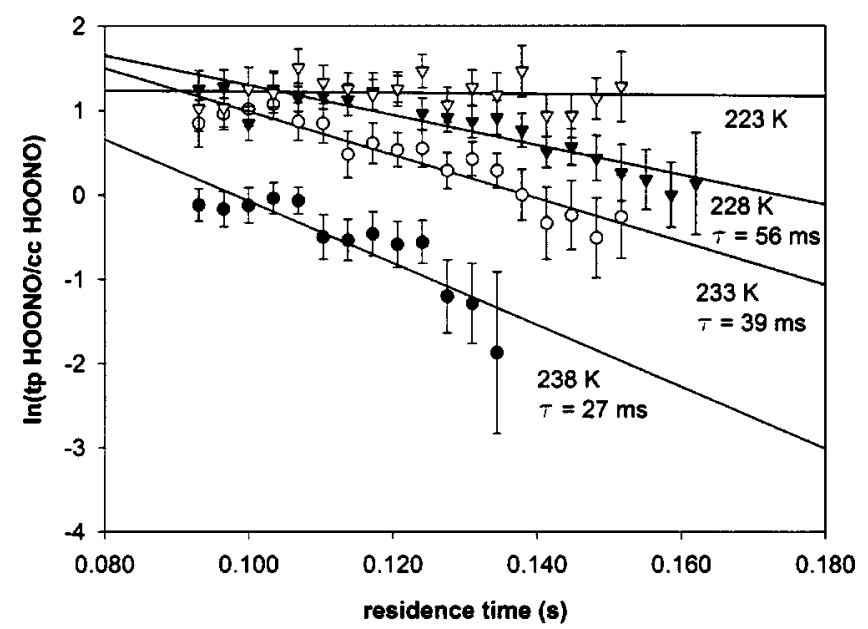

FIG. 7. Measurement of lifetimes of trans-perp HOONO in the flow cell at various temperatures. The measurement is done by monitoring the ratio of the relative intensities of the trans-perp HOONO to cis-cis HOONO overtone bands as a function of the flow cell residence time. The slope of each line is the decay rate in per second. 
TABLE I. Molecular constants for the cis-cis, trans-perp, and perp-perp conformers of HOONO computed at the $\operatorname{CCSD}(\mathrm{T}) / \mathrm{cc}-\mathrm{pVTZ}$ level, except for energies, which are reported at both the $\operatorname{CCSD}(\mathrm{T}) / \mathrm{cc}-\mathrm{pVTZ}$ and CCSD(T)/cc-pVQZ//CCSD(T)/cc-pVTZ levels, relative to the cis-cis HOONO energy at each level of theory.

\begin{tabular}{|c|c|c|c|}
\hline Geometries $^{\mathrm{a}}$ & $\begin{array}{l}\text { Cis-cis } \\
\text { HOONO }\end{array}$ & $\begin{array}{l}\text { Trans-perp } \\
\text { HOONO }\end{array}$ & $\begin{array}{c}\text { Anti-perp- } \\
\text { perp HOONO }\end{array}$ \\
\hline$R(\mathrm{HO} 1)(\AA)$ & 0.9823 & 0.9663 & 0.9662 \\
\hline$R(\mathrm{O} 1 \mathrm{O} 2)$ & 1.4332 & 1.4314 & 1.4384 \\
\hline$R(\mathrm{O} 2 \mathrm{~N})$ & 1.3845 & 1.4681 & 1.6070 \\
\hline$R(\mathrm{NO} 3)$ & 1.1917 & 1.1692 & 1.1512 \\
\hline$\theta(\mathrm{HO} 1 \mathrm{O} 2)$ & $99.80^{\circ}$ & $100.75^{\circ}$ & $100.57^{\circ}$ \\
\hline$\theta(\mathrm{O} 1 \mathrm{O} 2 \mathrm{~N})$ & $112.98^{\circ}$ & $105.50^{\circ}$ & $100.33^{\circ}$ \\
\hline$\theta(\mathrm{O} 2 \mathrm{NO} 3)$ & $114.39^{\circ}$ & $108.75^{\circ}$ & $109.74^{\circ}$ \\
\hline$\phi(\mathrm{HO} 1 \mathrm{O} 2 \mathrm{~N})$ & $0^{\circ}$ & $176.83^{\circ}$ & $82.65^{\circ}$ \\
\hline$\phi(\mathrm{O} 1 \mathrm{O} 2 \mathrm{NO} 3)$ & $0^{\circ}$ & $97.59^{\circ}$ & $97.00^{\circ}$ \\
\hline$A(\mathrm{MHz})$ & 21310 & 54127 & 24782 \\
\hline$B$ & 8081 & 4977 & 5896 \\
\hline C & 5859 & 4627 & 5326 \\
\hline \multicolumn{4}{|l|}{ Energetics $^{\mathrm{b}}$} \\
\hline \multicolumn{4}{|l|}{$\operatorname{CCSD}(\mathrm{T}) / \mathrm{cc}-\mathrm{pVTZ}$} \\
\hline$E_{\mathrm{el}}$ (hartrees) & -280.4736515 & -280.4674707 & -280.4503806 \\
\hline$\Delta E_{\mathrm{el}}(\mathrm{kJ} / \mathrm{mol})$ & 0 & 16.2 & 61.1 \\
\hline$\Delta E_{0}(\mathrm{~kJ} / \mathrm{mol})$ & 0 & 14.6 & 56.9 \\
\hline$\Delta H_{298}^{\circ}(\mathrm{kJ} / \mathrm{mol})$ & 0 & 15.9 & 57.0 \\
\hline \multicolumn{4}{|c|}{$\operatorname{CCSD}(\mathrm{T}) / \mathrm{cc}-\mathrm{pVQZ} / / \mathrm{CCSD}(\mathrm{T}) / \mathrm{cc}-\mathrm{pVTZ}$} \\
\hline$E_{\mathrm{el}}$ (hartrees) & -280.5603706 & -280.5544193 & -280.5373081 \\
\hline$\Delta E_{\mathrm{el}}(\mathrm{kJ} / \mathrm{mol})$ & 0 & 15.6 & 60.5 \\
\hline$\Delta E_{0}(\mathrm{~kJ} / \mathrm{mol})$ & 0 & 13.7 & 56.1 \\
\hline$\Delta H_{298}^{\circ}(\mathrm{kJ} / \mathrm{mol})$ & 0 & 15.3 & 56.4 \\
\hline \multicolumn{4}{|c|}{ Harmonic frequencies ${ }^{\mathrm{c}}\left(\mathrm{cm}^{-1}\right)$} \\
\hline$\nu_{1}$ & $3521\left(a^{\prime}\right)$ & 3780 & 3774 \\
\hline$\nu_{2}$ & $1630\left(a^{\prime}\right)$ & 1736 & 1794 \\
\hline$\nu_{3}$ & $1458\left(a^{\prime}\right)$ & 1412 & 1374 \\
\hline$\nu_{4}$ & $969\left(a^{\prime}\right)$ & 992 & 906 \\
\hline$\nu_{5}$ & $838\left(a^{\prime}\right)$ & 816 & 702 \\
\hline$\nu_{6}$ & $723\left(a^{\prime}\right)$ & 497 & 468 \\
\hline$\nu_{7}$ & $419\left(a^{\prime}\right)$ & 366 & 384 \\
\hline$\nu_{8}$ & $523\left(a^{\prime \prime}\right)$ & 302 & 288 \\
\hline$\nu_{9}$ & $383\left(a^{\prime \prime}\right)$ & 211 & $233 i$ \\
\hline
\end{tabular}

${ }^{\mathrm{a}}$ Atom labels are assigned as $\mathrm{HO} 1 \mathrm{O} 2 \mathrm{NO} 3$.

${ }^{\mathrm{b}}$ Zero point and enthalpy corrections to $E_{\text {el }}$ are determined from $\operatorname{CCSD}(\mathrm{T}) / \mathrm{cc}-\mathrm{pVTZ}$ frequencies.

${ }^{\mathrm{c}}$ Vibrational frequencies of cis-cis and trans-perp HOONO from Bean et al., Ref. 9.

the $6971 \mathrm{~cm}^{-1}$ trans-perp HOONO feature at room temperature, and decays much more slowly than trans-perp HOONO does at colder temperatures. We therefore assign all of the bands in the room temperature spectrum to the lowest-energy conformer, cis-cis HOONO.

A $3 \mathrm{~cm}^{-1}$ resolution action spectrum of the $6365 \mathrm{~cm}^{-1}$ cis-cis HOONO band is shown in Fig. 5(b) along with a rotational band shape simulation from the ASYROTWIN program. ${ }^{23}$ The upper and lower state rotational constants are taken from Table I, and a $b$-type band is assumed, based on calculations in Sec. IV D. The simulated cis-cis HOONO band has the pronounced $P$ and $R$ bands of a $b$-type transition, and is slightly broader than the trans-perp HOONO band, but the experimentally measured cis-cis HOONO band is significantly broader than predicted and has no resolvable structure. We conclude that some dynamical process, either IVR (intramolecular vibrational redistribution) or dissociation, is leading to the broadening and absence of rotational structure.

The cis-cis HOONO spectrum becomes progressively weaker at lower temperatures, most likely due to rapid wall loss. To observe the temperature dependence of the cis-cis HOONO spectrum over a larger temperature range, we employ an alternate synthesis of HOONO which does not require discharge chemistry (eliminating the need for long reaction times in the flow cell) and produces no detectable amount of trans-perp HOONO. HOONO is prepared by reacting $\mathrm{H}_{2} \mathrm{O}_{2}$ vapor with solid $\mathrm{NOBF}_{4}$ in situ, analogous to the production of $\mathrm{HO}_{2} \mathrm{NO}_{2}$ from $\mathrm{NO}_{2} \mathrm{BF}_{4}$ described in Ref. 24. Using this preparation method, we observe no temperature dependence of the relative peak intensities in the cis-cis HOONO spectrum in the range 193-273 K (Fig. 9).

Weaker new bands are observed in the discharge HOONO synthesis at 6250 and $7700 \mathrm{~cm}^{-1}$ (Fig. 3). The peak at $6250 \mathrm{~cm}^{-1}$ is only observed at cold temperatures, coincident with the trans-perp HOONO peak at $6971 \mathrm{~cm}^{-1}$, and is hence assigned to trans-perp HOONO. The temperature dependence of the $7700 \mathrm{~cm}^{-1}$ band was not studied systematically, therefore, this band cannot be assigned to either transperp or cis-cis HOONO. 


\section{B. OH product state distributions}

The large differences in the structure and binding energy of cis-cis and trans-perp HOONO suggest that these two conformers should have distinct vibrational predissociation dynamics. The dynamical differences in the quantum state distribution of $\mathrm{OH}$ photofragments can be used to assist in spectroscopic assignment of various HOONO bands and provide other useful information. Pollack et al. analyzed the $\mathrm{OH}$ state distribution from the photolysis of supersonically cooled HOONO in the $6971 \mathrm{~cm}^{-1}$ band to constrain its binding energy to $D_{0}<70.3 \mathrm{~kJ} / \mathrm{mol}$, consistent with an assignment of the band to the trans-perp, but not cis-cis, conformer of HOONO. ${ }^{17}$

In our experiment, the nascent energy distribution of the product $\mathrm{OH}$ fragments can be estimated by scanning over various $\mathrm{OH}$ lines with the LIF probe laser while the pump laser is fixed on a chosen $\mathrm{OH}$ overtone resonance of one of the HOONO conformers. To minimize thermalization of the $\mathrm{OH}$ prior to detection, the cell pressure and the pump-probe delay must be kept at their lowest possible values. The minimal pump-probe delay in this experiment is $50 \mathrm{~ns}$, limited primarily by jitter in the pump-probe separation (10 ns) and by temporal width of the UV probe laser pulse $(20 \mathrm{~ns})$. In Ar bath gas, the average rotational energy transfer rate constant for $\mathrm{OH}^{2} \Pi_{3 / 2}\left(v^{\prime \prime}=0\right)$, in $N^{\prime \prime}=1-5$, is 2.3 $\times 10^{-11} \mathrm{~cm}^{3}$ molecule ${ }^{-1} \mathrm{sec}^{-1} \cdot{ }^{25}$ At a pressure of $13 \mathrm{hPa}$, this corresponds to $\sim 0.5$ effective collisions between pump and probe pulses.

Despite this partial thermalization, a significantly different energy distribution in the $\mathrm{OH}$ photofragments is observed for the cis-cis and trans-perp conformers of HOONO. Figure 6 shows the observed distributions within the corresponding ${ }^{2} \Pi_{3 / 2}^{-}(N)$ rotational manifolds obtained from analysis of $Q_{11}(N)$ branch of the $A^{2} \Sigma(v=1) \leftarrow X^{2} \Pi(v=0)$ band. The $\mathrm{OH}$ fragments from the photodissociation of trans-perp $\mathrm{HOONO}$ are rotationally excited, while the $\mathrm{OH}$ fragments from cis-cis HOONO are concentrated more heavily in the lowest $N$ states, even though the cis-cis HOONO spectrum is recorded at a higher temperature. This distribution is consistent with the larger energy release $\left(h \nu-D_{0}\right)$ expected for trans-perp than for cis-cis HOONO based on the laser excitation energy and the empirically determined dissociation energies, providing further evidence that the transient feature observed is trans-perp HOONO.

\section{Trans-perp to cis-cis HOONO isomerization rate}

Flow cell kinetics experiments have been employed to measure the lifetime of trans-perp HOONO. At low temperatures, the signal from both conformers decays with residence time (distance from injector), but the trans-perp HOONO signal at $6971 \mathrm{~cm}^{-1}$ decays faster. The loss of cis-cis HOONO only occurs at temperatures below about $270 \mathrm{~K}$, and the loss rate increases with decreasing temperature. We therefore conclude that the cis-cis HOONO decay is due to diffusion to the walls and subsequent uptake or reaction, while the faster decay of the trans-perp HOONO signal is due to isomerization. If we assume that both conformers of HOONO have the same wall loss rates in the flow cell, then

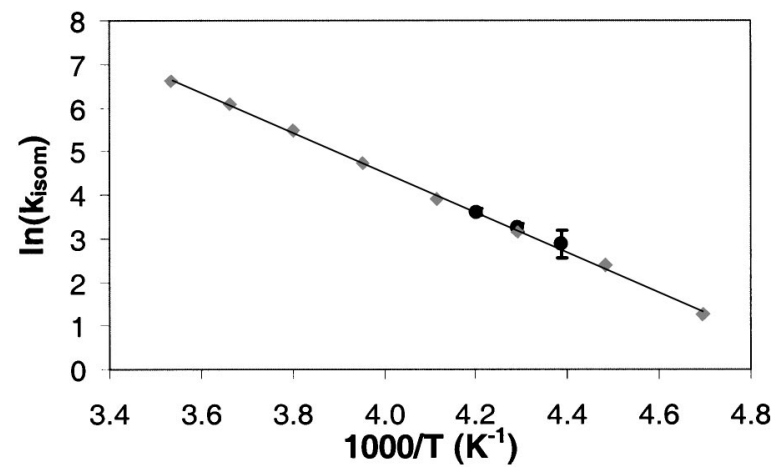

FIG. 8. Trans-perp to cis-cis HOONO isomerization rate as a function of temperature. Gray diamonds represent the results of a MULTIWELL simulation with an isomerization barrier of $40.8 \mathrm{~kJ} / \mathrm{mol}$ at $8.7 \mathrm{hPa}$. Black circles are experimental data. Fit to the experimental data gives an isomerization activation barrier of $E_{\text {act }}(230 \mathrm{~K})=33 \pm 12 \mathrm{~kJ} / \mathrm{mol}$.

the ratio of the trans-perp to cis-cis HOONO signals gives the trans-perp HOONO decay due to isomerization alone.

The relative ratio of intensities $I_{\mathrm{tp}} / I_{\mathrm{cc}}$ of trans-perp to cis-cis HOONO signal is monitored at a series of injector positions (residence times) in the flow cell at several temperatures by measurement of signal intensity $I$ at three wavelengths: one where both trans-perp and cis-cis HOONO absorb $\left(6971 \mathrm{~cm}^{-1}\right)$, one which determines the baseline absorption by cis-cis HOONO underneath the $6971 \mathrm{~cm}^{-1}$ signal $\left(6950 \mathrm{~cm}^{-1}\right)$, and one where only cis-cis HOONO signal is present $\left(6365 \mathrm{~cm}^{-1}\right)$ :

$$
\frac{I_{\mathrm{tp}}}{I_{\mathrm{cc}}}=\frac{I\left(6971 \mathrm{~cm}^{-1}\right)-I\left(6950 \mathrm{~cm}^{-1}\right)}{I\left(6935 \mathrm{~cm}^{-1}\right)} .
$$

In addition, we assume that the increase in cis-cis HOONO signal due to the isomerization is negligible, since the number density of trans-perp HOONO is significantly lower than that of cis-cis HOONO, and since the spectrum is spread over a broad $1000 \mathrm{~cm}^{-1}$ wavelength range compared to the spectrally narrow $30 \mathrm{~cm}^{-1}$ trans-perp peak. A plot of $\ln \left(I_{\mathrm{tp}} / I_{\mathrm{cc}}\right)$ versus residence time has a slope that is the unimolecular rate of trans-perp to cis-cis isomerization. Temperature-dependent isomerization rates are shown in Fig. 7 , in the range $223<T<238 \mathrm{~K}$.

The lifetimes of trans-perp HOONO at 238, 233, and $228 \mathrm{~K}$ are estimated to be $27 \pm 4,39 \pm 3$, and $56 \pm 6 \mathrm{~ms}$, respectively, at $13 \mathrm{hPa}$ of predominantly Ar. Unfortunately, we cannot probe the isomerization over a broader temperature range, because only one conformer can be detected with sufficient precision at colder and warmer temperatures. The data at $223 \mathrm{~K}$ show a very small slope and significant error; no accurate lifetime can be determined. The Arrhenius $\ln (k)$ versus 1/T relationship (Fig. 8) gives an activation energy for isomerization of $E_{\text {act }} \sim 33 \pm 12(1 \sigma) \mathrm{kJ} / \mathrm{mol}$. The large uncertainty stems from the narrow temperature range used to determine $E_{\text {act }}$. 


\section{COMPUTATIONAL RESULTS}

\section{A. Ab initio calculations of cis-cis, trans-perp, and perp-perp HOONO structures, energetics, and frequencies}

The structures, energies, and vibrational frequencies of the cis-cis, trans-perp, and (anti-)perp-perp HOONO conformers have been calculated by electronic structure theory using the program GAUSSIAN $98 .{ }^{26}$ For these calculations we use coupled cluster theory ${ }^{27}$ with single and double excitations, with perturbative estimates of connected triples CCSD(T). The calculations employ the Dunning correlation consistent polarized valence basis sets. The two basis sets used in this study are the cc-pVTZ basis set $(4 s 3 p 2 d 1 f$ for $\mathrm{C}, \mathrm{N}$, and $\mathrm{O} ; 3 s 2 p 1 d$ for $\mathrm{H}$ ) and the cc-pVQZ basis set $(5 s 4 p 3 d 2 f 1 g$ for $\mathrm{C}, \mathrm{N}$, and $\mathrm{O} ; 4 s 3 p 2 d 1 f$ for $\mathrm{H}){ }^{28,29}$

Optimized structures and vibrational frequencies of the three isomers are computed at the CCSD(T)/cc-pVTZ level. The perp-perp isomer possesses one imaginary frequency, corresponding to torsion of the heavy atoms (OONO). Energies at these geometries are computed at the $\operatorname{CCSD}(\mathrm{T}) / \mathrm{cc}-$ pVTZ and CCSD(T)/cc-pVQZ levels. Table I lists the structures, energies, rotational constants, and vibrational frequencies of the three conformers, with perp-perp HOONO computed in the anti configuration. The normal modes of the trans-perp and the perp-perp isomer are ordered in descending frequency, while the modes of the cis-cis isomer, which has $C_{s}$ symmetry, are first ordered based on the symmetry, $a^{\prime}$ and then $a^{\prime \prime}$. The $\operatorname{CCSD}(\mathrm{T}) / \mathrm{cc}-\mathrm{pVQZ} / / \operatorname{CCSD}(\mathrm{T}) / \mathrm{cc}-\mathrm{pVTZ}$ energies are consistent with QCISD and CCSD(T)/cc-pVTZ results reported previously. ${ }^{9}$

\section{B. Statistical (RRKM) calculations of isomerization rate}

To better understand the observed temperature dependence of the HOONO action spectrum, we model the isomerization rates of HOONO conformers using the program MULTIWELL (version 1.3.3) ${ }^{30}$ which uses a stochastic approach to solve RRKM master equations. The main goal of these simulations is to confirm that the experimentally determined rates of isomerization from the trans-perp conformer to the lowerenergy cis-cis conformer are consistent with the ab initio energetics of HOONO. We adopt the required RRKM parameters from the model developed by Golden, Barker and Lohr, ${ }^{2}$ which successfully reproduced the extensive kinetic data on the $\mathrm{OH}+\mathrm{NO}_{2}$ reaction (Hippler, Nasterlack and Striebel, ${ }^{3}$ and others). The dissociation energy of cis-cis HOONO is fixed at $83 \mathrm{~kJ} / \mathrm{mol}$ and the energy separation between trans-perp and cis-cis conformers is set to $15 \mathrm{~kJ} /$ mol. The average internal energy transferred per collision is chosen to be $\alpha=500 \mathrm{~cm}^{-1}$. The height of the transperp $\rightarrow$ cis-cis HOONO isomerization barrier (treated as a single transition state energy for both perp-perp states) is varied to reproduce the experimentally observed trans-perp isomerization rates. Because the reaction is in the low pressure limit, isomerization rates and collision parameter $\alpha$ are linearly related, and the trans-perp $\rightarrow$ cis-cis HOONO isomerization barrier determined is inversely correlated to the choice of $\alpha=500 \mathrm{~cm}^{-1}$. The simulation starts with the trans-perp conformer in an internally thermalized state, from which it can either reversibly isomerize into the cis-cis well or irreversibly dissociate into $\mathrm{OH}$ and $\mathrm{NO}_{2}$. For the range of probed barrier heights $(15-55 \mathrm{~kJ} / \mathrm{mol})$, the rate of dissociation into $\mathrm{OH}$ and $\mathrm{NO}_{2}$ is negligibly small compared to the rate of equilibration between cis-cis and trans-perp conformers of HOONO. Therefore, the simulated time dependence for the trans-perp concentration can be directly fitted to an exponential decay to extract the effective equilibration rate $\left(=k_{\mathrm{tp} \rightarrow \mathrm{cc}}+k_{\mathrm{cc} \rightarrow \mathrm{tp}} \approx k_{\mathrm{tp} \rightarrow \mathrm{cc}}\right)$.

The RRKM simulations of trans-perp to cis-cis HOONO isomerization presented here were performed assuming a bath gas of $\mathrm{N}_{2}$. Our experimental gas mixture, however, consists of small amounts of $\mathrm{H}_{2}$ and $\mathrm{NO}_{2}, 72 \% \mathrm{Ar}, 14 \% \mathrm{He}$, and $12 \% \mathrm{~N}_{2}$. Donahue et al. ${ }^{31}$ have shown that relative to a collisional efficiency of $\beta=1$ for nitrogen, $\beta(\mathrm{Ar})=0.61 \pm 0.03$ and $\beta(\mathrm{He})=0.48 \pm 0.03$, in the $\mathrm{OH}+\mathrm{NO}_{2}$ system. For the gas mixture used in these experiments, then, the collisional efficiency is $\beta \approx 0.65$. In the low pressure limit, which is applicable to these experiments at $13 \mathrm{hPa}$, this lower collision efficiency is equivalent to a lower pressure. Our gas mixture at $13 \mathrm{hPa}$ behaves equivalently to pure $\mathrm{N}_{2}$ at $8.7 \mathrm{hPa}$.

Figure 8 displays the calculated $k_{\mathrm{tp} \rightarrow \mathrm{cc}}$ isomerization rates at $8.7 \mathrm{hPa}$ of $\mathrm{N}_{2}$ as a function of temperature. The calculation uses the trans-perp $\rightarrow$ cis-cis HOONO isomerization barrier of $\Delta E_{0}=40.8 \mathrm{~kJ} / \mathrm{mol}$ (corresponding to an energy of $\Delta E_{0}=55.8 \mathrm{~kJ} / \mathrm{mol}$ for the perp-perp isomer relative to the cis-cis HOONO energy). The modeled trans-perp to cis-cis HOONO barrier height is in excellent agreement with the energy computed here at the $\operatorname{CCSD}(\mathrm{T}) / \mathrm{cc}-\mathrm{pVQZ} / /$ $\operatorname{CCSD}(\mathrm{T}) / \mathrm{cc}-\mathrm{pVTZ}$ level, $\Delta E_{0}=42.4 \mathrm{~kJ} / \mathrm{mol}$, and is also consistent with the energy computed by Golden, Barker, and Lohr $^{2}$ at the QCISD(T)/cc-pVDZ level (double $\zeta$ ), $45.3 \mathrm{~kJ} /$ mol, for perp-perp HOONO relative to trans-perp HOONO.

The predicted temperature dependence of the isomerization rates compares favorably with the experimental results (black points in Fig. 8, derived from Fig. 7). The value suggested by our MULTIWELL simulations $(40.8 \mathrm{~kJ} / \mathrm{mol})$ is within the error limits of the experimentally determined activation energy $\left(E_{\text {act }}=33 \pm 12 \mathrm{~kJ} / \mathrm{mol}\right)$.

\section{Calculated photodissocation quantum yields and temperature dependence of relative band intensities in cis-cis HOONO}

We also use MULTIWELL to predict the effective photodissociation quantum yields for the overtone transitions of cis-cis HOONO. The results of these simulations are shown in Figs. 9(a) and 9(b). In these simulations, the internal energy distribution for thermalized cis-cis HOONO is abruptly shifted upward by the photon energy. The fraction of HOONO conformers and $\mathrm{OH}+\mathrm{NO}_{2}$ products formed after 100 collisions following the excitation is taken as the yield. We use $D_{0}($ cis-cis HO-ONO $)=83 \mathrm{~kJ} / \mathrm{mol}\left(6940 \mathrm{~cm}^{-1}\right)$, which represents the best ab initio estimate from Dixon et al. ${ }^{10}$ as well as the empirical value determined by extrapolation to $0 \mathrm{~K}$ from high-temperature data from Hippler, Nasterlack, and Striebel. ${ }^{3}$

Figure 9(a) depicts the fraction of cis-cis and trans-perp $\mathrm{HOONO}$ as well as $\mathrm{OH}+\mathrm{NO}_{2}$ produced as a function of 

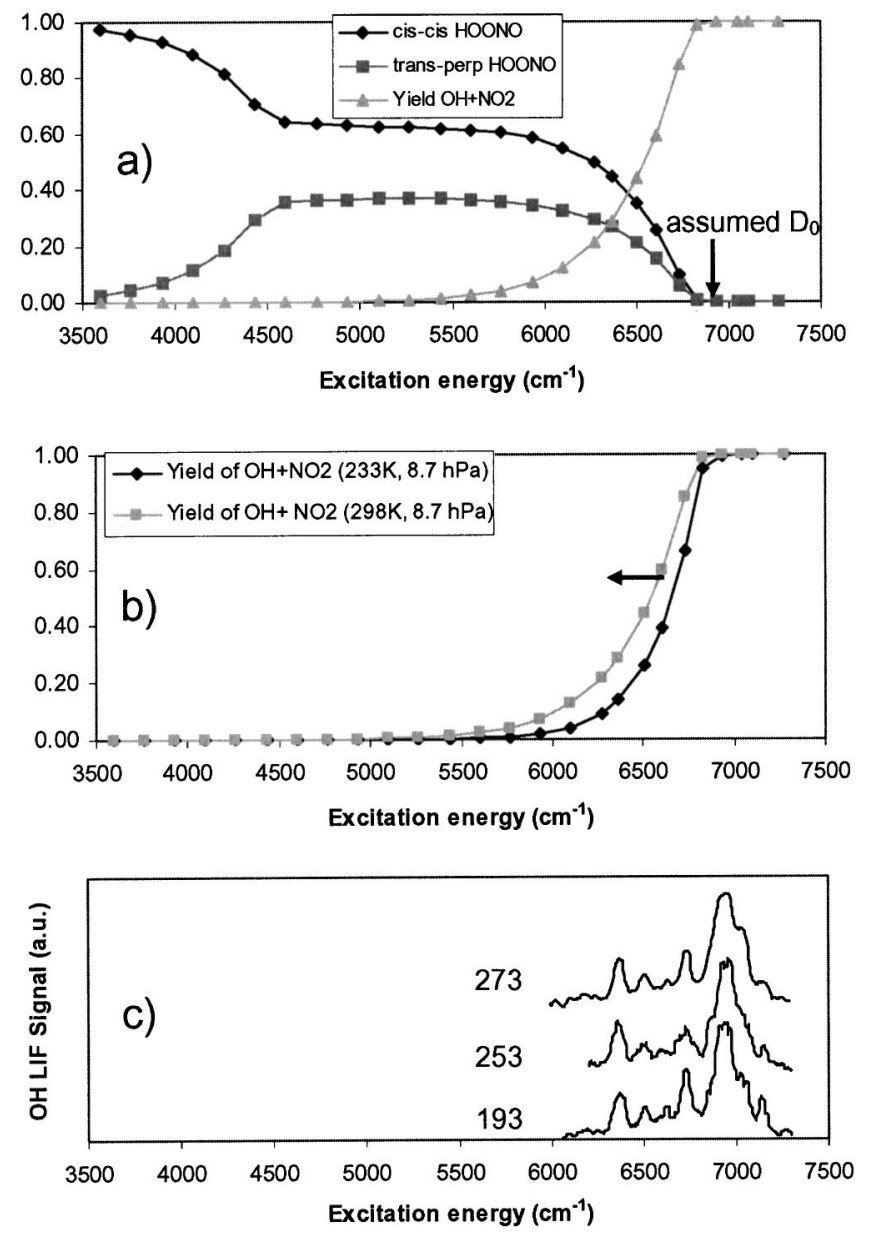

FIG. 9. Simulation of the quantum yield of cis-cis HOONO, trans-perp $\mathrm{HOONO}$, and $\mathrm{OH}+\mathrm{NO}_{2}$ products, following vibrational excitation of cis-cis $\mathrm{HOONO}$ at $298 \mathrm{~K}$ as a function of excitation energy. Calculations assume a dissociation energy of $D_{0}$ (cis-cis HOONO $)=83 \mathrm{~kJ} / \mathrm{mol}\left(6940 \mathrm{~cm}^{-1}\right.$, shown with arrow). A significant yield of trans-perp HOONO is predicted after excitation above the isomerization barrier. The onset of dissociation occurs at $5500 \mathrm{~cm}^{-1}$, well below the dissociation threshold. Calculations are run at $8.7 \mathrm{hPa} \mathrm{N}$ (equivalent to $13 \mathrm{hPa}$ of the gas mixture used in the above experiments, see text). (b) Photodissociation quantum yield as a function of excitation energy, calculated at 233 and $298 \mathrm{~K}$, with $D_{0}($ cis-cis $\mathrm{HOONO})=83 \mathrm{~kJ} / \mathrm{mol}$. The quantum yield at the $6365 \mathrm{~cm}^{-1}$ peak is predicted to double when the temperature is changed from 233 to 298 K. (c) Experimentally measured cis-cis HOONO spectrum at three temperatures. The relative strengths of the bands in the cis-cis HOONO spectrum do not change appreciably over the temperature range 193-273 K.

energy added to the system at $298 \mathrm{~K}$. When the system is excited above the isomerization barrier between 4500 and $6000 \mathrm{~cm}^{-1}$, a significant amount of the original cis-cis HOONO isomerizes, forming a sizable fraction of trans-perp HOONO products as determined by the density of states at the isomerization barrier energy. Photodissociation products begin to appear at $5500 \mathrm{~cm}^{-1}$, with the yield slowly rising to $\sim 50 \%$ at $6600 \mathrm{~cm}^{-1}$ (still well below $D_{0}$ ). The quantum yield is predicted to approach unity at $6700 \mathrm{~cm}^{-1}$.

Figure 9(b) compares the $\mathrm{OH}+\mathrm{NO}_{2}$ yield for two temperatures representative of our experimental conditions. Over the frequency range of the observed cis-cis HOONO spectrum, we find that the quantum yield for photodissociation increases from $30 \%$ to $100 \%$ at $298 \mathrm{~K}$ and from $15 \%$ to $100 \%$ at $233 \mathrm{~K}$. At the $6365 \mathrm{~cm}^{-1}$ peak, the quantum yield is predicted to double from 233 to $298 \mathrm{~K}$. Thus, the simulations predict that the relative intensities of the bands should change markedly as a function of temperature.

Figure 9(c) shows the positions of the cis-cis HOONO bands on the scale of the quantum yield predictions, and also illustrates the insensitivity of the spectrum to temperature change. We observe no discernable change in relative integrated peak intensities in the cis-cis HOONO spectrum over the range 193-273 K.

\section{Calculated transition strengths of cis-cis and trans-perp HOONO}

To estimate the relative concentrations of the cis-cis and trans-perp HOONO from the observed band intensities, we perform semiempirical calculations to compute transition strengths for the observed overtone bands of both isomers. We test the validity of our normal mode anharmonic oscillator and Morse oscillator approaches by calculating band intensities of the $\nu_{1}$ and $2 \nu_{1}$ transition of nitric acid, for which experimentally determined oscillator strengths and further predictions are available.

The method of using $a b$ initio dipole moment functions in calculating vibrational band intensities has been demonstrated. $^{32,33}$ Vibrational band intensity calculations similar to those reported here have been performed by Kjaergaard, Henry, and others on several molecules using a local mode harmonically coupled anharmonic oscillator model $^{34-36}$ and coupled Morse oscillators. ${ }^{37}$ For calculation of the $\mathrm{OH}$ fundamental and overtone in HOONO described here, we consider only the $\mathrm{OH}$ normal mode.

The oscillator strength for a given vibrational transition is given by

$$
f_{f i}=\frac{4 \pi m_{e}}{3 e^{2} \hbar} \nu_{f i} \sum_{i=a, b, c}\left|M_{i}\right|^{2},
$$

where $\nu_{f i}$ is the frequency of the transition and $M_{i}$ are the matrix elements of the transition dipole moment between the ground and excited vibrational states:

$$
M_{i}=\left\langle f\left|\mu_{i}\right| i\right\rangle \text {. }
$$

The values of the matrix elements $M_{i}$ for the $v=0 \rightarrow 2$ overtone transitions are obtained by first computing $a b$ initio dipole moment functions along one dimension, the normal mode $q_{1}$ (essentially the $\mathrm{OH}$ stretch). The vibrational matrix elements are then calculated using two different onedimensional models, an anharmonic oscillator model with a single cubic perturbation, and the Morse oscillator model, where the parameters for both models are fit using observed vibrational energies.

Dipole moment functions are calculated for both cis-cis and trans-perp HOONO structures using the GAUSSIAN98 program. ${ }^{26}$ Optimized structures for each isomer are first determined at the B3LYP/AUG-cc-pVTZ, MP2/AUG-ccpVTZ, MP3/AUG-cc-pVDZ, and QCISD/AUG-cc-pVDZ levels of theory (where AUG denotes diffuse function augmented basis sets). The atoms are then displaced in 0.1 $\mathrm{amu}^{1 / 2} \AA$ increments (Note: GAUSSIAN 98 normal mode outputs are in Cartesian coordinates. Conversion to $a m u^{1 / 2} \AA$ 
TABLE II. Computed dipole moment functions in Debye for trans-perp and cis-cis conformers of HOONO as a function of normal mode displacement $q_{1}$. Taylor series coefficients were derived from the fitting of a fifth-order polynomial (see text) to ab initio dipole moments at nine points along the $q_{1}$ normal mode, computed in $0.1 \mathrm{amu}^{1 / 2} \AA$ increments in the range $-0.4 \mathrm{amu}^{1 / 2} \AA<\Delta q_{1}<+0.4 \mathrm{amu}^{1 / 2} \AA$. Coefficients are defined as $c_{i, n}=(1 / n !)\left(\partial^{n} \mu_{i} / \partial q_{1}^{n}\right)$, where $i=A, B, C$, the principal axes. Units are $D \mathrm{amu}^{-n / 2} \AA^{-n}$.

\begin{tabular}{|c|c|c|c|c|}
\hline & $\begin{array}{c}\text { B3LYP } \\
\text { AUG-cc-pVTZ }\end{array}$ & $\begin{array}{c}\text { MP2 } \\
\text { AUG-cc-pVTZ }\end{array}$ & $\begin{array}{c}\text { MP3 } \\
\text { AUG-cc-pVDZ }\end{array}$ & $\begin{array}{c}\text { QCISD } \\
\text { AUG-cc-pVDZ }\end{array}$ \\
\hline \multicolumn{5}{|l|}{ Trans-perp HOONO } \\
\hline Reduced mass (amu) & 1.0686 & 1.0686 & 1.0684 & 1.0685 \\
\hline$\left|\mu_{\text {tot }}\right|$ (equil) & 1.7330 & 1.8758 & 2.0498 & 1.9724 \\
\hline$\mu_{0, A}$ & 0.7470 & 0.6909 & 1.0488 & 0.8562 \\
\hline$c_{A, 1}$ & 0.8067 & 0.9256 & 0.8837 & 0.9043 \\
\hline$c_{A, 2}$ & -0.6961 & -0.8855 & -0.8046 & -0.8230 \\
\hline$c_{A, 3}$ & -2.6773 & -0.3270 & -0.2301 & -0.2139 \\
\hline$c_{A, 4}$ & -5.5369 & 0.0499 & -0.0640 & -0.0526 \\
\hline$c_{A, 5}$ & 14.9472 & 0.5069 & 0.7197 & 0.6901 \\
\hline$\mu_{0, B}$ & -0.3478 & -0.6010 & -0.5989 & -0.6306 \\
\hline$c_{B, 1}$ & -0.0320 & -0.0569 & -0.1604 & -0.1009 \\
\hline$c_{B, 2}$ & 0.4737 & 0.2048 & 0.1460 & 0.1860 \\
\hline$c_{B, 3}$ & -0.1344 & -0.0882 & -0.1097 & -0.1006 \\
\hline$c_{B, 4}$ & -1.9665 & -0.0123 & -0.0001 & 0.0150 \\
\hline$c_{B, 5}$ & 0.5710 & -0.0568 & -0.2200 & -0.1946 \\
\hline$\mu_{0, C}$ & 1.5310 & 1.6370 & 1.6557 & 1.6609 \\
\hline$c_{C, 1}$ & 0.8302 & 1.1023 & 1.1150 & 1.1205 \\
\hline$c_{C, 2}$ & -0.5782 & -0.2726 & -0.2353 & -0.2249 \\
\hline$c_{C, 3}$ & -1.1973 & -0.7564 & -0.7030 & -0.6433 \\
\hline$c_{C, 4}$ & -0.6951 & 0.1149 & 0.2032 & 0.2490 \\
\hline$c_{C, 5}$ & 0.6047 & 0.5634 & 0.4862 & 0.2819 \\
\hline \multicolumn{5}{|l|}{ Cis-cis HOONO } \\
\hline Reduced mass (amu) & 1.0643 & 1.0640 & 1.0642 & 1.0641 \\
\hline$\left|\mu_{\text {tot }}\right|$ (equil) & 0.9618 & 1.1744 & 1.1987 & 1.2276 \\
\hline$\mu_{0, A}$ & -0.4042 & -0.7435 & -0.7513 & -0.8604 \\
\hline$c_{A, 1}$ & -0.5378 & -0.7808 & -0.7929 & -0.8628 \\
\hline$c_{A, 2}$ & -3.4439 & -1.1959 & -1.2353 & -1.3039 \\
\hline$c_{A, 3}$ & 3.4255 & -0.2171 & -0.1870 & -0.2322 \\
\hline$c_{A, 4}$ & 14.5912 & 0.0450 & -0.1166 & -0.0649 \\
\hline$c_{A, 5}$ & -28.5687 & 0.2815 & 0.3832 & 0.4338 \\
\hline$\mu_{0, B}$ & -0.9096 & -0.9090 & -0.9337 & -0.8753 \\
\hline$c_{B, 1}$ & -0.4418 & -1.1157 & -1.0871 & -1.0676 \\
\hline$c_{B, 2}$ & -1.3162 & -0.0838 & -0.0801 & -0.0926 \\
\hline$c_{B, 3}$ & -2.9383 & -0.3229 & -0.3965 & -0.4281 \\
\hline$c_{B, 4}$ & 12.6755 & -0.2311 & -0.1332 & -0.1372 \\
\hline$c_{B, 5}$ & -2.8530 & -0.2012 & -0.3487 & -0.3588 \\
\hline$\mu_{0, C}$ & 0 & 0 & 0 & 0 \\
\hline$c_{C, 1}$ & 0 & 0 & 0 & 0 \\
\hline$c_{C, 2}$ & 0 & 0 & 0 & 0 \\
\hline$c_{C, 3}$ & 0 & 0 & 0 & 0 \\
\hline$c_{C, 4}$ & 0 & 0 & 0 & 0 \\
\hline$c_{C, 5}$ & 0 & 0 & 0 & 0 \\
\hline
\end{tabular}

units, and conversion of dipole derivatives to $D \mathrm{amu}^{n / 2} \AA^{-n}$ units, was done after calculation.) from the optimized geometries along the $q_{1}$ normal mode to generate nine structures along the vibrational mode $\left(+0.4 \mathrm{amu}^{1 / 2} \AA>\Delta q_{1}>-0.4\right.$ $\mathrm{amu}^{1 / 2} \AA$ ). This normal mode displacement involves primarily motion of the $\mathrm{H}$ atom along the $\mathrm{OH}$ bond, with small concomitant motion of the adjacent $\mathrm{O}$ atom. The dipole moments are computed for each of these nine structures, for each principal axis component $(i)$, at each level of theory. These points are then fit to a Taylor series expansion, truncated after the fifth derivative, to extract the derivatives of the dipole moment function used in the transition moment calculation:

$$
\mu_{i}=\mu_{0, i}+\sum_{n=1}^{5} \frac{1}{n !} \frac{\partial^{n} \mu_{i}}{\partial q^{n}} q^{n}=\mu_{0, i}+\sum_{n=1}^{n} c_{i, n} q^{n}
$$

Table II lists $\mu_{0, i}$ and coefficients $c_{i, n}$ at all levels of theory used. Also listed is $\mu_{1}$, the effective reduced mass of the mode $q_{1}$, computed in the GAUSSIAN 98 program at each level of the theory. ${ }^{38,39}$

We have found that the dipole moment function predicted by the hybrid density functional theory (DFT) B3LYP method does not vary smoothly with $q_{1}$. Thus, DFT does not seem to be adequate for calculating the dipole moments of HOONO. The erratic variations in electric moment is evi- 
TABLE III. Observed vibrational bands, and fitted harmonic frequencies and anharmonicities $\left(\mathrm{cm}^{-1}\right)$ for the stable conformers of HOONO.

\begin{tabular}{lcccc}
\hline \hline & $\nu_{1}$ & $2 \nu_{1}$ & $\omega_{e}$ & $\omega_{e} x_{e}$ \\
\hline Cis-cis HOONO & $3306^{\mathrm{a}}$ & $6365^{\mathrm{b}}$ & 3548 & 121 \\
Trans-perp HOONO & $3574^{\mathrm{c}}$ & $6971^{\mathrm{d}}$ & 3751 & 88.5 \\
\hline \hline
\end{tabular}

${ }^{\mathrm{a}}$ Reference 9 .

${ }^{\mathrm{b}}$ Reference 11 and this work.

${ }^{c}$ Based on $a b$ initio frequency, Ref. 9, and matrix isolation spectrum, Ref. 19.

${ }^{\mathrm{d}}$ Reference 17 and this work.

dence of orbital switching and/or configuration mixing in HOONO, which suggests that a single configuration method is inadequate to describe the wave functions of either conformer of HOONO. While the DFT method has been reported to predict dipole moment functions for molecules such as $\mathrm{H}_{2} \mathrm{O}$ that can be accurately described by a single configuration, ${ }^{40}$ it does not seem to predict accurate dipole moments functions for HOONO, particularly in the hydrogen-bonded cis-cis conformer. Kjaergaard et al. have observed the same inadequacy of DFT in determination of electrostatic moments in systems with hydrogen bonding in the case of the water dimer. ${ }^{41}$

Our $a b$ initio calculations predict that trans-perp HOONO has a larger permanent dipole moment than cis-cis HOONO, and one that points predominantly along the $c$ axis of the molecule. The permanent dipole moment in cis-cis HOONO roughly bisects the $a$ and $b$ axes in the plane of the molecule and points towards the terminal $\mathrm{O}$ with a slightly larger component along the $b$ axis than the $a$ axis. These principal axes are shown in Fig. 1. The first derivatives of the dipole moment can be used to estimate the transition strength of the $\nu_{1}$ fundamental band in the harmonic limit, and compared to transition strengths determined from analytical gradients computed at the equilibrium geometry. For both transperp and cis-cis HOONO, at the MP2/AUG-cc-pVTZ, MP3/ AUG-cc-pVDZ, and QCISD/AUG-cc-pVDZ levels of theory, our numerical derivatives give transition strengths that are roughly a factor of 2 larger than those calculated from single-point analytic derivatives. This discrepancy suggests the degree to which the single-point methods diverge from an explicit calculation of the dipole moment function over a larger geometry change.

In the first approach to calculate transition strengths, we treat the $\mathrm{OH}$ normal mode as an anharmonic oscillator with a single cubic perturbation term, and obtain anharmonic wave functions by fitting the predicted energy levels (diagonalizing the Hamiltonian to $v=12$ ) to observed $\nu_{1}$ and $2 \nu_{1}$ band positions (Table III). The fundamental of trans-perp HOONO has not yet been observed in the gas phase, so we estimate it to be $3574 \mathrm{~cm}^{-1}$ from prior $a b$ initio predictions, ${ }^{15}$ which are consistent with the observed Ar matrix frequency. ${ }^{19}$ The $2 \nu_{1}$ transition moments are then obtained by numerical integration over the fitted dipole moment function and anharmonic initial and final state wave functions.

In the second approach, we calculate the overtone transition moments assuming the $\mathrm{OH}$ stretch could be modeled as a Morse oscillator fit to $\omega_{e} x_{e}$ and $\omega_{e}$ parameters derived from observed $\nu_{1}$ and $2 \nu_{1}$ band positions for cis-cis HOONO, and predicted $\nu_{1}$ and observed $2 \nu_{1}$ band positions for trans-perp HOONO. We use expressions for the Morse oscillator transition matrix elements of first, second, and third order given by Gallas. ${ }^{42}$

To examine the validity of these two methods, we compute the oscillator strengths for both the fundamental and first overtone of nitric acid, for which extensive experimental and computational results are available. We compute the dipole moment function for nitric acid at the MP2/AUG-ccpVTZ level of theory over the same $+0.4 \mathrm{amu}^{1 / 2} \AA>\Delta q_{1}$ $>-0.4 \mathrm{amu}^{1 / 2} \AA$ range.

For the fundamental $\nu_{1} \mathrm{OH}$ transition in nitric acid, Lange et al. ${ }^{43}$ find an oscillator strength of $f_{10}=1.07$ $\times 10^{-5}\left(\tilde{\sigma}_{10}=9.46 \times 10^{-18} \mathrm{~cm}^{2} /\right.$ molecule $\left.\mathrm{cm}\right)$, while Chackerian, Sharpe, and Blake ${ }^{44}$ obtain $f_{10}=1.40 \times 10^{-5}\left(\tilde{\sigma}_{10}\right.$ $=1.24 \times 10^{-17} \mathrm{~cm}^{2} /$ molecule $\left.\mathrm{cm}\right)$. Our anharmonic oscillator method gives $f_{10}=2.60 \times 10^{-5}$, while the Morse oscillator method gives $f_{10}=5.06 \times 10^{-5}$. A recent single-point $a b$ initio prediction ${ }^{9}$ of the $\mathrm{OH}$ fundamental intensity in the double harmonic approximation yielded $f_{10}=1.69 \times 10^{-5}$ (90 km/mol).

The oscillator strength of the first overtone band of nitric acid is also known experimentally and has been calculated previously. The experimental oscillator strength is $f_{20}$ $=3.75 \times 10^{-7}\left(\tilde{\sigma}_{20}=3.32 \times 10^{-19} \mathrm{~cm}^{2} /\right.$ molecule $\left.\mathrm{cm}\right)$, as determined by Lange et al. ${ }^{43}$ The oscillator strength calculated by the anharmonic oscillator method presented here is $f_{20}$ $=2.26 \times 10^{-7}$, while the prediction from the Morse oscillator method is $f_{20}=4.49 \times 10^{-7}$. Other $a b$ initio techniques predicted yet higher oscillator strengths for the first overtone of nitric acid. Donaldson et al. ${ }^{45}$ compute $f_{20}=5.96 \times 10^{-7}$ at the QCISD/6-31+ $\mathrm{G}(d, p)$ level (unscaled). Rong et al. calculate $f_{20}=7.11 \times 10^{-7}$ at the QCISD/6-311+ $+\mathrm{G}(2 d, 2 p)$ level using an empirical Deng-Fan potential, and $f_{20}=6.05 \times 10^{-7}$ using a Morse oscillator approach. ${ }^{46}$

The results of both the anharmonic and Morse oscillator approaches for HOONO are given in Table IV. The difference in the anharmonic and Morse oscillator results indicate the accuracy of modeling transitions in the lowest vibrational levels. We note that this simple treatment does well at these low vibrational levels. The relative transition strengths of cis-cis to trans-perp HOONO $2 \nu_{1}$ bands for both methods and all four levels of theory used are listed in Table V. In all cases, the B3LYP method does not give reliable single-point dipole moments for HOONO, and the resulting transition dipole matrix elements and oscillator strengths deviate significantly from the MP2 and higher level results. We therefore do not use the B3LYP results to compute transition strengths. Both the anharmonic oscillator and the Morse oscillator method predict a stronger $2 \nu_{1}$ transition for transperp than for cis-cis HOONO, by a factor of 3.7:1 and 3.2:1, respectively, at the QCISD/AUG-cc-pVDZ level. The methods agree reasonably well, with the Morse oscillator method predicting consistently higher transition dipole moments and oscillator strengths.

The QCISD level anharmonic oscillator calculation predicts that the $2 \nu_{1}$ spectrum of trans-perp HOONO should be 
TABLE IV. Calculated values of the transition dipole moment matrix elements $M_{i}$, oscillator strengths $f$, and rovibrational hybrid band types for the $2 \nu_{1}$ overtone transitions of trans-perp and cis-cis HOONO. Matrix elements were computed by integrating ab initio dipole moment functions using both anharmonic oscillator and Morse oscillator methods. Units of $M_{A}, M_{B}$, and $M_{C}$ are Debye; units of $\left|M_{\text {tot }}\right|^{2}$ are Debye $e^{2}$

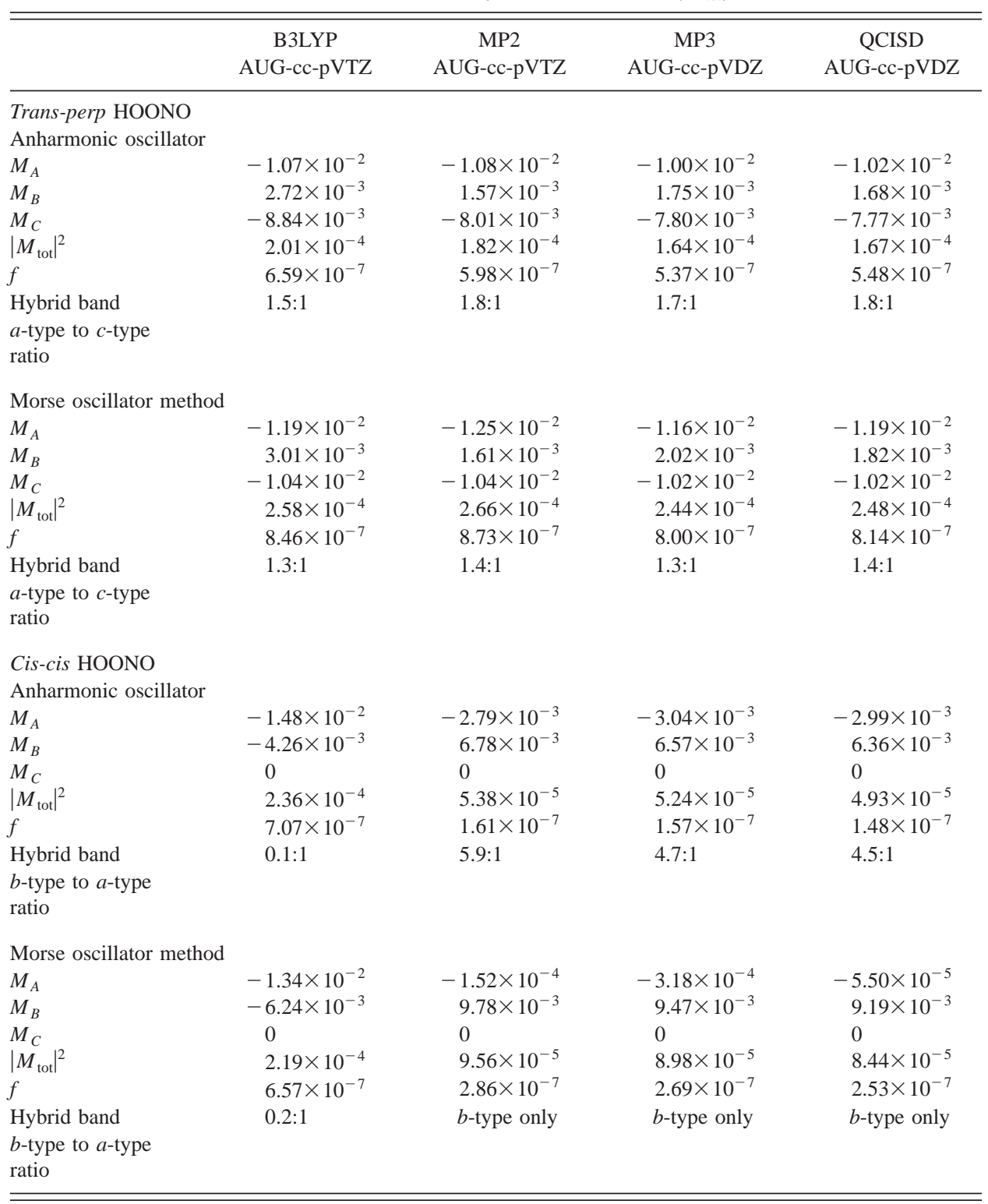

a hybrid band with a ratio $1.8: 1 a$-type to $c$-type. Figure 5(a) shows that a band contour simulation agrees very well with the experimental spectrum. This ratio also agrees with the approximate experimental ratio of 1:1 adopted by Pollack et al. ${ }^{17}$ for the same transition. In the case of cis-cis HOONO, no structure is observed on the $2 \nu_{1}$ band in this experiment, hence, there is no experimental test for the QCISD/AUG-cc-pVDZ calculated hybrid band $b$-type to $a$-type ratio of 4.5 to 1 . Bean et al. ${ }^{9}$ find that a range of ratios of $b$-type to $a$-type from 1 to 4 provide an acceptable fit to their cavity ring down spectrum of $\nu_{1}$ (cis-cis HOONO). Our anharmonic method predicts a $b$-type to $a$-type ratio of 2 for

TABLE V. Ratio of $2 \nu_{1}$ overtone oscillator strength for trans-perp vs cis-cis HOONO at each level of theory.

\begin{tabular}{|c|c|c|c|c|}
\hline & \multicolumn{4}{|c|}{ Oscillator strength ratio (tp:cc ratio) } \\
\hline & $\begin{array}{c}\text { B3LYP/ } \\
\text { AUG-cc-pVTZ }\end{array}$ & $\begin{array}{c}\text { MP2/ } \\
\text { AUG-cc-pVTZ }\end{array}$ & $\begin{array}{c}\text { MP3/ } \\
\text { AUG-cc-pVDZ }\end{array}$ & $\begin{array}{c}\text { QCISD/ } \\
\text { AUG-cc-pVDZ }\end{array}$ \\
\hline $\begin{array}{l}\text { Anharmonic } \\
\text { oscillator method }\end{array}$ & $0.9: 1$ & $3.7: 1$ & $3.4: 1$ & $3.7: 1$ \\
\hline $\begin{array}{l}\text { Morse oscillator } \\
\text { method }\end{array}$ & $1.3: 1$ & $3.0: 1$ & $3.0: 1$ & $3.2: 1$ \\
\hline
\end{tabular}


the fundamental $\mathrm{OH}$ stretch of cis-cis HOONO, consistent with the experimental bounds.

\section{E. Relative populations of cis-cis and trans-perp HOONO}

In principle, the initial populations of the two conformers of HOONO can be estimated using the computed oscillator strengths, if we assume that all long-lived peaks in the HOONO spectrum belong to cis-cis HOONO and derive their intensity from the $2 \nu_{1}$ transition. At the earliest time in the flow cell at which HOONO can be observed, the ratio of the integrated area of the cis-cis conformer bands to that of the trans-perp bands is about 5:1 at $233 \mathrm{~K}$. With the relative transition strength of trans-perp to cis-cis HOONO of 3.7:1 and assuming unit photodissociation quantum yield for both species, this leads to an approximate upper bound on the initial cis-cis to trans-perp HOONO concentration ratio of 19:1. This supports the assumption that no rise in cis-cis HOONO signal should be detectable due to isomerization, since $n_{\mathrm{tp}} \ll n_{\mathrm{cc}}$.

This estimate is only an upper bound on the true initial cis-cis to trans-perp HOONO concentration ratio, because there is a sizable delay between when reaction occurs and when HOONO concentrations are probed. As seen in Fig. 7, the shortest residence time is $80 \mathrm{~ms}$, based on the estimated flow velocity and injector/laser-interaction region distance. This residence time is on the same order of magnitude as the observed isomerization lifetimes; thus, a significant fraction of trans-perp HOONO will have isomerized prior to the laser measurement. However, our estimate of residence time is qualitative. The injector flow velocity is significantly greater than the velocity of background $\mathrm{NO}_{2} / \mathrm{N}_{2}$ gas mixture entering the flow cell. Thus, it is possible that the formation of $\mathrm{OH}$ and subsequent reaction with $\mathrm{NO}_{2}$ occurs over a range of distances from the injector inlet. This does not adversely impact our measured isomerization rates, since the transperp HOONO lifetime data show completely single exponential behavior.

\section{DISCUSSION}

\section{A. Kinetics scheme for HOONO formation and isomerization}

The experimental results and RRKM simulations reported here confirm the kinetics scheme for formation of HOONO shown in Fig. 10, developed by Golden, Barker, and Lohr. ${ }^{2}$

Collisional stabilization forms an initially energy-rich HOONO far above the cis-cis $\leftrightarrow$ trans-perp HOONO isomerization barrier (but below the barrier for dissociation back into $\mathrm{OH}$ and $\mathrm{NO}_{2}$ ). The isomerization rates between the two isomers are substantially faster than the collision rate at 13 $\mathrm{hPa}$; thus the isomers are in microcanonical equilibrium with relative populations determined by the specific density of states. The two isomers remain in microcanonical equilibrium as they are collisionally relaxed, until the internal energy approaches the barrier height (the two nearly isoenergetic perp-perp isomers). Further collisions then relax HOONO below the isomerization barrier, and rapidly form

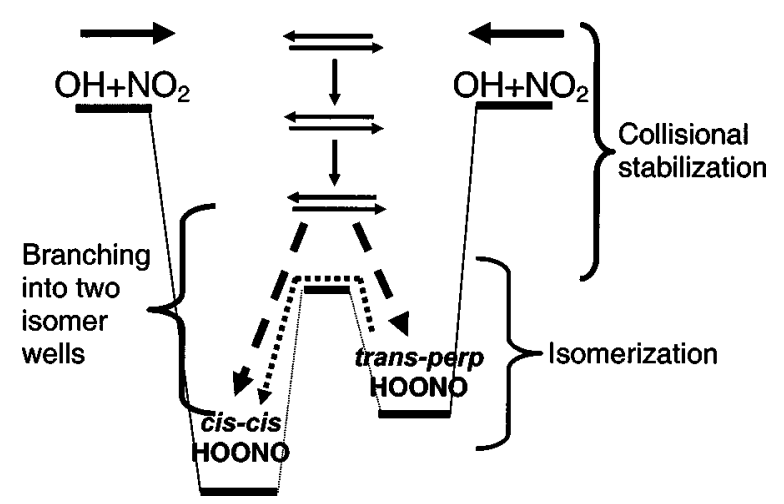

FIG. 10. Proposed kinetic scheme for $\mathrm{OH}+\mathrm{NO}_{2} \rightarrow \mathrm{HOONO}$ formation. The initially produced HOONO has enough internal energy for a facile isomerization between the cis-cis HOONO and trans-perp HOONO wells. After a few collisions, the system relaxes into the wells with a comparable yield of both conformers. Slow isomerization from the trans-perp HOONO into the cis-cis HOONO well then occurs on the millisecond time scale.

thermalized cis-cis and trans-perp isomers. This picture is illustrated by our RRKM simulation (Fig. 9), where we find that if HOONO is placed in either cis-cis or trans-perp HOONO well at any energy between isomerization and dissociation barriers, the system promptly relaxes below the isomerization barrier into both wells after just a few collisions (at $T=230 \mathrm{~K}$ and $P=13 \mathrm{hPa}$ in $\mathrm{N}_{2}$ buffer).

The initial ratio of the thermalized conformers formed is thus determined by the relative density of states of the two isomers at the perp-perp isomer barrier energy, which statistical modeling of the experimentally measured rates predicts to be $40.8 \mathrm{~kJ} / \mathrm{mol}$ above the trans-perp energy. This ratio is predicted to be 2:1 cis-cis HOONO to trans-perp HOONO using the densities of states from Golden, Barker, and Lohr. ${ }^{2}$ Thus, the initial population of trans-perp HOONO is substantially higher than expected from a Boltzmann distribution $(<1 \%)$. The high relative abundance of the less stable trans-perp isomer arises because the trans-perp HOONO density of states rises more rapidly with energy than that of cis-cis HOONO. Our own $233 \mathrm{~K}$ estimate of this cis-cis to trans-perp HOONO ratio is 19:1, measured at a distance $\sim 80 \mathrm{~ms}$ downstream from the discharge inlet in the flow cell. This result confirms that substantial population of transperp $\mathrm{HOONO}$ is formed at temperatures below $233 \mathrm{~K}$.

This nonthermal population of trans-perp HOONO subsequently relaxes to cis-cis HOONO by isomerization. Our experiment shows that the HOONO population shifts to the cis-cis HOONO well (thermal equilibrium) within $\sim 100 \mathrm{~ms}$ (at $13 \mathrm{hPa}$ ), consistent with RRKM modeling.

\section{B. Spectral assignment of the cis-cis HOONO action spectrum}

The room temperature HOONO action spectrum comprises several bands with no resolvable structure. The intensity pattern is also unusual, with the strongest band at 6935 $\mathrm{cm}^{-1}$. Nizkorodov and Wennberg ${ }^{11}$ tentatively assigned these bands to three conformers of HOONO: cis-cis, cis-perp, and trans-perp HOONO. We have found that all features in the spectrum observed above $240 \mathrm{~K}$ arise from the same conformer. We have also observed that trans-perp HOONO can- 
not give rise to any of these features, since this conformer is observed only transiently at lower temperatures. Finally, recent calculations ${ }^{2,10}$ indicate that cis-perp HOONO is not a stable isomer.

We therefore propose that these bands be assigned to the $2 \nu_{1}$ overtone and $2 \nu_{1}$-containing combination bands and/or sequence bands of cis-cis HOONO. Based on our observations and calculations, we suggest possible new assignments for the cis-cis HOONO action spectrum. It must be emphasized that these are tentative assignments.

We assign the first strong peak, at $6365 \mathrm{~cm}^{-1}$, to the origin of the cis-cis HOONO overtone $\left(2 \nu_{1}\right)$. The position, $580 \mathrm{~cm}^{-1}$ lower in energy than the $2 \nu_{1}$ origin of nitric acid, is in accord with our expectations for the overtone of the hydrogen-bonded $\mathrm{OH}$ stretch in cis-cis HOONO. Bean et al. ${ }^{9}$ have observed that the band origin of the fundamental $1 \nu_{1}$ band is redshifted by $\sim 250 \mathrm{~cm}^{-1}$ from the free $\mathrm{OH}$ stretch of nitric acid. The somewhat larger anharmonic correction, $\omega_{e} x_{e}=121 \mathrm{~cm}^{-1}$ (Table III), is expected with internal hydrogen bonding.

This $6365 \mathrm{~cm}^{-1}$ band is featureless and appears to be broadened significantly compared to the expected width of the rotational band contour [Fig. 5(b)]; the other bands in the room temperature spectrum have similar widths. In contrast, the observed band of the trans-perp isomer is well fit by the predicted rotational band contour. These observations indicate that the cis-cis conformer of HOONO must undergo relatively rapid IVR, leading to intrinsic line broadening beyond the width predicted on the basis of the predicted rotational band contour. The rapid IVR may be due to the presence of the intramolecular hydrogen bond in the cis-cis conformer, since hydrogen bonds greatly enhance coupling of the $\mathrm{OH}$ stretching vibration to the lower-frequency modes.

Computed frequencies provide some guidance in assigning the remaining bands. The highest level theoretical frequencies computed to date are shown in Table I. The four lowest-frequency modes for cis-cis $\mathrm{HOONO}$ are the two inplane $a^{\prime}$ modes, the NO stretch $\left(\nu_{6}\right)$ and the NOO bend/ intermolecular $\mathrm{OH} \cdots \mathrm{O}$ stretch $\left(\nu_{7}\right)$, and the two out-ofplane $a^{\prime \prime}$ modes, the ONOO torsion $\left(\nu_{8}\right)$ and the HOON torsion $\left(\nu_{9}\right)$. Examination of the normal mode displacements indicates that the two torsional modes are thoroughly mixed. However, these are harmonic predictions of modes with large amplitude displacements and may have significant uncertainty.

One possible assignment relies on matching the observed band positions to the above $a b$ initio frequencies. We then assign $2 \nu_{1}+\nu_{9}$ to the $6730 \mathrm{~cm}^{-1}$ band, $2 \nu_{1}+\nu_{8}$ to the broad $6935 \mathrm{~cm}^{-1}$ band, and $2 \nu_{1}+\nu_{6}$ to the $7045 \mathrm{~cm}^{-1}$ band. Bands at 6180,6505 , and $6630 \mathrm{~cm}^{-1}$, close to the pure $2 \nu_{1}$ band, would then be assigned as torsional sequence bands of $2 \nu_{1}$.

The difficulty with this assignment is the anomalous intensity pattern of the room temperature cis-cis HOONO spectrum. One normally expects the $2 \nu_{1}$ origin to be the strongest band, since the $\mathrm{OH}$ stretch is the only expected bright state at this energy. However, the band at $6935 \mathrm{~cm}^{-1}$ is $\sim$ three times stronger.

The most plausible explanation is that the action spec- trum does not reproduce the absorption strengths, because the quantum yield for dissociation is not unity across this wavelength range. Our statistical calculations (Fig. 9) show that, if the dissociation energy of cis-cis HOONO is $83 \mathrm{~kJ} /$ mol $\left(6940 \mathrm{~cm}^{-1}\right),{ }^{3}$ then the lower-frequency bands are suppressed due to nonunity quantum yield. At our assigned origin of the $2 \nu_{1}$ transition frequency, $6365 \mathrm{~cm}^{-1}$, only $\sim 30 \%$ of the cis-cis HOONO molecules will dissociate upon photon excitation at room temperature.

However, these calculations also predict that the quantum yield of the origin band will increase significantly (a factor of two) from 233 to $298 \mathrm{~K}$, while we observe that all bands in this spectrum scale together over the temperature range 193-273 K.

It is possible that a coincidence of two effects leads to this observation. If the higher-energy band(s) around 6935 $\mathrm{cm}^{-1}$ are hot bands $(v>0)$ which only have sufficient thermal population of the excited initial state to be observed at higher temperatures, then the intensity of these bands will decrease as the temperature is lowered. The lower-energy bands will decrease with lowering temperature due to the temperature dependence of the quantum yield, and if these two temperature effects coincide, no apparent change in relative band intensity would be observed.

It is also possible that the assumed $83 \mathrm{~kJ} / \mathrm{mol}$ dissociation energy is too high. Lowering the dissociation energy in the model would simply shift the $\mathrm{OH}+\mathrm{NO}_{2}$ photodissociation yield curve down the frequency axis, and a shift of 5 $\mathrm{kJ} / \mathrm{mol}$ [indicated by an arrow in Fig. 9(b)] would lead to near-unity quantum yield over all bands in the cis-cis HOONO spectrum and no temperature dependence of the relative peak intensities. This would give an experimental upper limit on the cis-cis HOONO bond dissociation energy of $D_{0}$ (cis-cis HO-ONO $) \leqslant 78 \mathrm{~kJ} / \mathrm{mol}\left(6520 \mathrm{~cm}^{-1}\right)$.

If $D_{0}$ (cis-cis $\left.\mathrm{HO}-\mathrm{ONO}\right) \leqslant 78 \mathrm{~kJ} / \mathrm{mol}$, the anomalously high intensity of the $6935 \mathrm{~cm}^{-1}$ band requires explanation. The intensity of this band may result from strong coupling of the $\mathrm{OH}$ stretch with other degrees of freedom, especially the $\mathrm{OH}$ torsional mode. The strength of this $6935 \mathrm{~cm}^{-1}$ band might be reasonable if it is a superposition of several combination bands of the form $2 \nu_{1}+n \nu_{9}$, and the $\mathrm{OH}-$ torsion coupling is strong. Multidimensional potential and dipole surfaces, as demonstrated successfully for CH-stretching overtone spectra of methyl rotors, ${ }^{47}$ would be required to fully analyze this coupling.

Our experimental evidence is not sufficient to determine the dissociation energy for cis-cis HOONO. Direct absorption measurements of cis-cis HOONO in the overtone energy regime are currently underway; these measurements would not be subject to quantum yield considerations, and would assist in assigning this spectrum.

\section{Atmospheric implications}

Isomerization of trans-perp to cis-cis HOONO occurs in milliseconds, even at low pressure. As a result, only the ciscis conformer of HOONO will have appreciable concentration in Earth's atmosphere. In addition, the collisional isomerization rate is sufficiently fast that trans-perp HOONO will not be present at significant concentrations in 
gas cell studies near room temperature. For example, Bean et $a l .{ }^{9}$ have reported cavity ring down spectroscopy (CRDS) of cis-cis HOONO, and determined a branching ratio of reaction (1a) and (1b). This branching ratio assumes that all HOONO is present in the cis-cis form on the 50-200 ms time scale of the CRDS experiment, since the HOONO yield is determined from the integrated cis-cis HOONO band. In CRDS, trans-perp HOONO signal would be buried in the extremely strong $\mathrm{HONO}_{2}$ band, and hence difficult to discern. The fast trans-perp to cis-cis isomerization rates determined here support the assumption made by Bean et al. to derive the $\mathrm{HOONO}$ to $\mathrm{HONO}_{2}$ branching ratio.

Our study allows estimation of the cis-cis HOONO lifetime in Earth's atmosphere. This lifetime is derived from a calculation similar to that used to predict the $\mathrm{HO}_{2} \mathrm{NO}_{2}$ near-IR photolysis lifetime. ${ }^{48}$ Excitation of $2 \nu_{1}$ and companion bands will be an efficient loss mechanism for HOONO. The average solar radiance at $1.4 \mu \mathrm{m}$ is 4.90 $\times 10^{13}$ photons $\mathrm{cm}^{-2} \mathrm{~s}^{-1} / \mathrm{cm}^{-1} .{ }^{49}$ The predicted oscillator strength of $1.5 \times 10^{-7}$ gives an integrated band intensity for cis-cis HOONO of $1.3 \times 10^{-19} \mathrm{~cm}^{2}$ molecule $\mathrm{cm}^{-1}$. Assuming unit quantum yield for photodissociation, the resulting photolysis rate of HOONO in the atmosphere due only to IR excitation will be $\sim 6 \times 10^{-6} \mathrm{~s}^{-1}$, leading to an upper limit estimate for the cis-cis HOONO lifetime of $1.6 \times 10^{5} \mathrm{~s}$ (less than 45 daylight hours). Other losses (e.g., thermal decomposition, UV photolysis, and reaction with $\mathrm{OH}$ ) will shorten this lifetime further. For example, using the kinetic parameters from Golden, Barker and Lohr, ${ }^{2}$ we predict that HOONO thermal decomposition lifetimes range from a few seconds at the surface to $3.3 \times 10^{6} \mathrm{~s}$ (38 days) at the tropopause. Thermal decomposition is the dominant removal mechanism in the lower troposphere.

The short lifetime of HOONO suggests that its photochemistry will not be of major importance in Earth's atmosphere. Consider the polar lower stratosphere in summer-a region and time characterized by both fast gas-phase formation of $\mathrm{HNO}_{3}$ and temperatures that are cold enough to yield a long HOONO thermal lifetime. At $20 \mathrm{~km}$ altitude, where [OH] concentrations are $\sim 2 \times 10^{6}$ molecules $\mathrm{cm}^{-3}$ ( $1 \mathrm{pptv}$ ), the reaction of $\mathrm{OH}$ with $\mathrm{NO}_{2}$ proceeds at a rate of $\sim 1$ $\times 10^{4}$ molecules $\mathrm{cm}^{-3} \mathrm{~s}^{-1} .50$ Assuming a $10 \%$ yield of HOONO in this reaction and the maximum HOONO lifetime $\left(1.6 \times 10^{5} \mathrm{~s}\right)$, the upper limit for the concentration of HOONO is $1.6 \times 10^{8}$ molecules $\mathrm{cm}^{-3}$, or $80 \mathrm{pptv}$. This concentration of HOONO may be detectable via remote measurement in the IR or far-IR but we stress this is an upper limit and UV photolysis and reaction with $\mathrm{OH}$ will certainly lead to lower abundances. In the troposphere, thermal decomposition will reduce its concentration further and therefore HOONO is unlikely to influence tropospheric chemistry appreciably. Thus, unless other major sources of HOONO exist, it is unlikely to play a major role in the atmospheric photochemistry.

\section{CONCLUSIONS}

We have observed both stable conformers of HOONO, cis-cis and trans-perp, formed as products in the reaction $\mathrm{OH}+\mathrm{NO}_{2}+M$ in a low pressure discharge flow cell. The two isomers are distinguished by their $2 \nu_{1}$ overtone spectra recorded by action spectroscopy, leading to a new understanding of earlier tentative spectral assignments. The transperp HOONO $2 \nu_{1}$ band is a sharp feature at $6971 \mathrm{~cm}^{-1}$, observed only at temperatures below $240 \mathrm{~K}$ and at a frequency consistent with the spectrum reported by Pollack et $a l .{ }^{17}$ We have reassigned all of the bands observed in the room temperature overtone spectrum to cis-cis HOONO. We find that under thermal reaction conditions, the trans-perp isomer is initially formed at high, non-Boltzmann populations relative to cis-cis HOONO; the trans-perp HOONO then quickly isomerizes to the more stable cis-cis conformer.

We have studied the isomerization of trans-perp to ciscis HOONO both experimentally and computationally. From our experimental measurements of the trans-perp HOONO decay, we find an isomerization lifetime of $39 \mathrm{~ms}$ at $233 \mathrm{~K}$. From the isomerization data over the temperature range 223-238 K, we estimate the activation energy for trans-perp to cis-cis HOONO isomerization to be $E_{\text {act }} \sim 33$ $\pm 12 \mathrm{~kJ} / \mathrm{mol}$, consistent with a strong collision model as shown by statistical modeling. We have performed master equation modeling of the isomerization; we find a barrier height of $40.8 \mathrm{~kJ} / \mathrm{mol}$, consistent with experimental data. Finally, we have performed CCSD(T)/cc-pVQZ//CCSD(T)/ccpVTZ $a b$ initio calculations of the perp-perp HOONO isomer, the transition state for isomerization. We obtain an activation enthalpy of $\Delta H_{298}^{\ddagger 0}=41.1 \mathrm{~kJ} / \mathrm{mol}$, in good agreement with both experiment and statistical modeling.

We have calculated the $\mathrm{OH}+\mathrm{NO}_{2}$ photodissociation quantum yield as a function of excitation energy in the near-IR based on the best published $a b$ initio and kinetics estimate of $D_{0}$ (cis-cis $\left.\mathrm{HOONO}\right)=83 \mathrm{~kJ} / \mathrm{mol}$, and find nonunity quantum yield predicted for some of the observed lower-frequency bands of cis-cis HOONO. We predict that the quantum yields should be sensitive to temperature, and that the apparent band strengths should change over the temperature range measured; however, we have not observed significant changes in the cis-cis HOONO spectrum from 193 to $273 \mathrm{~K}$, suggesting that quantum yield is in fact unity for all bands. It is possible that relative intensity changes cannot be unambiguously observed with our present signalto-noise ratios.

We have computed the relative transition strengths of the two conformers, and estimated the abundance of trans-perp HOONO relative to cis-cis HOONO. Semiempirical transition strength calculations using QCISD/AUG-cc-pVDZ level $a b$ initio dipole moment functions predict that the $2 \nu_{1}$ band of trans-perp HOONO absorbs more strongly than the $2 \nu_{1}$ band of cis-cis HOONO, with a relative strength of 3.7 calculated using an anharmonic oscillator model and a relative strength of 3.2 calculated using a Morse oscillator model. B3LYP level calculations fail to produce reliable single-point calculations of dipole moment functions, while MP2, MP3, and QCISD level calculations predict consistent dipole moment functions. Using the calculated relative transition strength of trans-perp to cis-cis HOONO of 3.7:1 and assuming unit photodissociation quantum yield for both species, we determine an approximate upper bound on the initial cis-cis to trans-perp HOONO concentration ratio of 19:1. 
The $213 \mathrm{~K}$ spectrum of trans-perp HOONO can be fit well to the predicted rotational constants, with a hybrid band ratio of 1.8:1 $a$-type to $c$-type, consistent with the simulation parameters that fit the Pollack et al. ${ }^{17}$ jet-cooled spectrum. We support the assignment by Nizkorodov and Wennberg ${ }^{11}$ of the $6365 \mathrm{~cm}^{-1}$ band to the origin of the cis-cis $2 \nu_{1}$ overtone band. However, this band is broad and featureless, suggesting that cis-cis HOONO undergoes much more rapid IVR upon overtone excitation. We cannot make a definitive assignment of the remaining bands observed in the cis-cis spectrum.

Based on its calculated $2 \nu_{1}$ transition strength, the more stable cis-cis HOONO is predicted to exist in the atmosphere at maximum concentrations of only $1.6 \times 10^{8}$ molecules $\mathrm{cm}^{-3}$ (80 pptv), and therefore, will be of limited importance in photochemical processes. For atmospheric chemistry, the most important impact of the formation of the short-lived HOONO reservoir is that the yield for radical loss via $\mathrm{OH}$ $+\mathrm{NO}_{2}$ is not unity.

\section{ACKNOWLEDGMENTS}

This material is based upon work supported under a National Science Foundation Graduate Research Fellowship (J.L.F.) and supported by NSF's Atmospheric Chemistry program (Contract No. ATM-0094670) and the NASA Upper Atmospheric Research Program (Contract No. NAG511657). S.A.N. thanks the Camille and Henry Dreyfus Postdoctoral Program in Environmental Chemistry for support. The authors thank J. R. Barker for providing MULTIWELL input files and H. G. Kjaergaard, I. M. Konen, I. B. Pollack, E. X. J. Li, and M. I. Lester for insightful discussions.

${ }^{1}$ D. M. Golden and G. P. Smith, J. Phys. Chem. A 104, 3991 (2000).

${ }^{2}$ D. M. Golden, J. R. Barker, and L. L. Lohr, J. Phys. Chem. A 107, 11057 (2003).

${ }^{3}$ H. Hippler, S. Nasterlack, and F. Striebel, Phys. Chem. Chem. Phys. 4, 2959 (2002).

${ }^{4}$ D. M. Matheu and W. H. Green, Int. J. Chem. Kinet. 32, 245 (2000).

${ }^{5}$ J. Troe, Int. J. Chem. Kinet. 33, 878 (2001).

${ }^{6}$ D. Fulle, H. F. Hamann, H. Hippler, and J. Troe, J. Chem. Phys. 108, 5391 (1998).

${ }^{7}$ N. M. Donahue, R. Mohrschladt, T. J. Dransfield, J. G. Anderson, and M. K. Dubey, J. Phys. Chem. A 105, 1515 (2001).

${ }^{8}$ J. S. Robertshaw and I. W. M. Smith, J. Phys. Chem. 86, 785 (1982).

${ }^{9}$ B. D. Bean, A. K. Mollner, S. A. Nizkorodov, G. Nair, M. Okumura, S. P. Sander, K. A. Peterson, and J. S. Francisco, J. Phys. Chem. A 107, 6974 (2003).

${ }^{10}$ D. A. Dixon, D. Feller, C. G. Zhan, and J. S. Francisco, J. Phys. Chem. A 106, 3191 (2002).

${ }^{11}$ S. A. Nizkorodov and P. O. Wennberg, J. Phys. Chem. A 106, 855 (2002).

${ }^{12}$ M. P. McGrath and F. S. Rowland, J. Phys. Chem. 98, 1061 (1994).

${ }^{13}$ H. W. Jin, Z. Z. Wang, Q. S. Li, and X. R. Huang, Theochem-J. Mol. Struct. 624, 115 (2003).

${ }^{14}$ H. H. Tsai, T. P. Hamilton, J. H. M. Tsai, M. vanderWoerd, J. G. Harrison,
M. J. Jablonsky, J. S. Beckman, and W. H. Koppenol, J. Phys. Chem. 100, 15087 (1996).

${ }^{15}$ Y. M. Li and J. S. Francisco, J. Chem. Phys. 113, 7976 (2000).

${ }^{16}$ H. Hippler, S. Krasteva, S. Nasterlack, and F. Striebel (private communication).

${ }^{17}$ I. B. Pollack, I. M. Konen, E. X. J. Li, and M. I. Lester, J. Chem. Phys. 119, 9981 (2003).

${ }^{18}$ R. S. Zhu and M. C. Lin, J. Chem. Phys. 119, 10667 (2003).

${ }^{19}$ B. M. Cheng, J. W. Lee, and Y. P. Lee, J. Phys. Chem. 95, 2814 (1991).

${ }^{20}$ P. O. Wennberg, R. C. Cohen, N. L. Hazen et al., Rev. Sci. Instrum. 65, 1858 (1994)

${ }^{21}$ S. Wu, G. A. Blake, Z. Y. Sun, and J. W. Ling, Appl. Opt. 36, 5898 (1997).

${ }^{22}$ L. S. Rothman, C. P. Rinsland, A. Goldman et al., J. Quant. Spectrosc. Radiat. Transf. 60, 665 (1998).

${ }^{23}$ R. H. Judge and D. J. Clouthier, Comput. Phys. Commun. 135, 293 (2001).

${ }^{24}$ R. A. Kenley, P. L. Trevor, and B. Y. Lan, J. Am. Chem. Soc. 103, 2203 (1981).

${ }^{25}$ D. A. V. Kliner and R. L. Farrow, J. Chem. Phys. 110, 412 (1999).

${ }^{26}$ M. J. Frisch, G. W. Trucks, H. B. Schlegel et al. GAUsSIAN 98, Revision A.9, 1998.

${ }^{27}$ K. Raghavachari, G. W. Trucks, J. A. Pople, and M. Head-Gordon, Chem. Phys. Lett. 157, 479 (1989)

${ }^{28}$ T. H. Dunning, Jr., J. Chem. Phys. 90, 1007 (1989).

${ }^{29}$ R. A. Kendall, T. H. Dunning, Jr., and R. J. Harrison, J. Chem. Phys. 96, 6796 (1992)

${ }^{30}$ J. R. Barker, Int. J. Chem. Kinet. 33, 232 (2001).

${ }^{31}$ N. M. Donahue, M. K. Dubey, R. Mohrschladt, K. L. Demerjian, and J. G. Anderson, J. Geophys. Res., [Atmos.] 102, 6159 (1997).

${ }^{32}$ H. G. Kjaergaard, K. J. Bezar, and K. A. Brooking, Mol. Phys. 96, 1125 (1999).

${ }^{33}$ H. G. Kjaergaard, C. D. Daub, and B. R. Henry, Mol. Phys. 90, 201 (1997).

${ }^{34}$ H. G. Kjaergaard, B. R. Henry, and A. W. Tarr, J. Chem. Phys. 94, 5844 (1991).

${ }^{35}$ H. G. Kjaergaard, H. T. Yu, B. J. Schattka, B. R. Henry, and A. W. Tarr, J. Chem. Phys. 93, 6239 (1990).

${ }^{36}$ D. M. Turnbull, H. G. Kjaergaard, and B. R. Henry, Chem. Phys. 195, 129 (1995).

${ }^{37}$ H. G. Kjaergaard, J. Phys. Chem. A 106, 2979 (2002).

${ }^{38}$ J. W. Ochterski, Gaussian White Paper 1999.

${ }^{39}$ E. B. Wilson, J. C. Decius, and P. C. Cross, Molecular Vibrations (McGraw-Hill, New York, 1955).

${ }^{40}$ C. H. Choi and M. Kertesz, J. Phys. Chem. 100, 16530 (1996).

${ }^{41}$ H. G. Kjaergaard, G. R. Low, T. W. Robinson, and D. L. Howard, J. Phys. Chem. A 106, 8955 (2002).

${ }^{42}$ J. A. C. Gallas, Phys. Rev. A 21, 1829 (1980).

${ }^{43}$ K. R. Lange, N. P. Wells, K. S. Plegge, and J. A. Phillips, J. Phys. Chem. A 105, 3481 (2001).

${ }^{44}$ C. Chackerian, S. W. Sharpe, and T. A. Blake, J. Quant. Spectrosc. Radiat. Transf. 82, 429 (2003).

${ }^{45}$ D. J. Donaldson, J. J. Orlando, S. Amann, G. S. Tyndall, R. J. Proos, B. R. Henry, and V. Vaida, J. Phys. Chem. A 102, 5171 (1998).

${ }^{46}$ Z. M. Rong, H. G. Kjaergaard, and M. L. Sage, Mol. Phys. 101, 2285 (2003).

${ }^{47}$ Z. Rong, D. L. Howard, and H. G. Kjaergaard, J. Phys. Chem. A 107, 4607 (2003).

${ }^{48}$ R. J. Salawitch, P. O. Wennberg, G. C. Toon, B. Sen, and J. F. Blavier, Geophys. Res. Lett. 29, 1762 (2002).

${ }^{49}$ C. W. Allen, Allen's Astrophysical Quantities (Springer, New York, 2000).

${ }^{50}$ T. F. Hanisco, E. J. Lanzendorf, P. O. Wennberg et al., J. Phys. Chem. A 105, $1543(2001)$. 